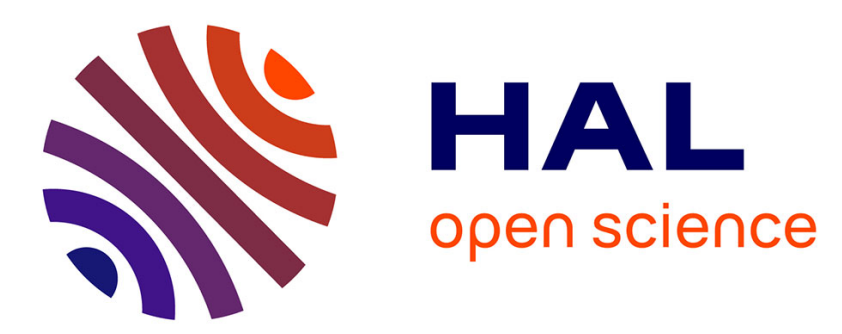

\title{
Analysis of Exposure to Solar and Galactic Cosmic Radiations of Flights Representative of the European International Air Traffic
}

Guillaume Hubert, Sébastien Aubry

\section{- To cite this version:}

Guillaume Hubert, Sébastien Aubry. Analysis of Exposure to Solar and Galactic Cosmic Radiations of Flights Representative of the European International Air Traffic. Radiation Research, 2018, 190 (3), pp.271-281. 10.1667/rr15095.1 . hal-01985774

\section{HAL Id: hal-01985774 https://hal.science/hal-01985774}

Submitted on 18 Jan 2019

HAL is a multi-disciplinary open access archive for the deposit and dissemination of scientific research documents, whether they are published or not. The documents may come from teaching and research institutions in France or abroad, or from public or private research centers.
L'archive ouverte pluridisciplinaire HAL, est destinée au dépôt et à la diffusion de documents scientifiques de niveau recherche, publiés ou non, émanant des établissements d'enseignement et de recherche français ou étrangers, des laboratoires publics ou privés. 


\title{
Analysis of Exposure to Solar and Galactic Cosmic Radiations of
}

\section{flights representative of the European international air traffic}

\author{
Guillaume HUBERT ${ }^{1, *}$ and Sébastien AUBRY ${ }^{1}$
}

${ }^{1}$ ONERA, the French Aerospace Lab,

2 avenue Edouard Belin, 31055 Toulouse Cedex 4, France

*Corresponding author

E-mail: Guillaume.Hubert@onera.fr ; sebastien.aubry@onera.fr

Running title: Analysis of Exposure to Solar and Galactic Cosmic Radiations 
Hubert G, Aubry S; Analysis of Exposure to Solar and Galactic Cosmic Radiations of flights representative of the European international air traffic, Radiat. Res.

Abstract - This paper analyzes the galactic and the solar cosmic rays impacts on ambient dose equivalent on flights. A high statistic of flights is considered, representative to the European international air traffic. Paths are issued from the Eurocontrol Demand Data Repository and consider realistic flight plan with and without regulations or updated with Radar Data from Central Flow Management Unit. Ambient dose equivalent during flights are investigated during quiet solar periods and extreme solar flare events. Thus, statistical analyses are presented, considering route characteristics (departure, arrival, continent etc.) and space weather conditions. Results show an important impact of the flight path, particularly the latitude which drives the cutoff rigidity variations. Moreover, dose values vary drastically during Ground Level Enhancement events, with the route path (latitude, longitude altitude) and the phasing of the solar event. This study highlights the importance of monitoring these solar events and to develop physical approach to obtain reliable assessment of ambient dose equivalents. 


\section{INTRODUCTION}

The Earth is constantly bombarded by cosmic rays (CR) that can be of either galactic or solar origin. Thus, aircraft expose humans to high levels of Galactic radiation correlated with the altitude and magnetic latitude. National and international agencies established recommended dose limits for both workers and publics. Then, national or continental regulations are established on these recommended dose limits.

The ambient dose equivalent is commonly used to assess the biological effect in radiation fields. It represents the dose equivalent that would be produced by the corresponding expanded and aligned field at a depth of $10 \mathrm{~mm}$ in an ICRU sphere with a diameter of $30 \mathrm{~cm}$. Thus, the typical total ambient dose equivalent for a transatlantic flight is about $50 \mu \mathrm{Sv}$ during quiet solar activity. On the contrary, estimations differ by one order of magnitude for the contribution induced by certain solar particle events (1). During a Ground Level Enhancements (GLE) event, the Sun can indeed emit particles of sufficient energy and intensity to raise radiation levels on Earth's surface. Analyses of GLE characteristics occurring since 1942 showed that for the worst of them, the dose level was of the order of $1 \mathrm{mSv}$ and more. The largest of these events was observed on February 1956 (2)(3) for which the ambient dose equivalent rate is in the orders of $10 \mathrm{mSv} \cdot \mathrm{hr}^{-1}$. The extra dose at aircraft altitudes for a flight during this event might have been about 20 $\mathrm{mSv}$, i.e. comparable with the annual limit for aircrew (4)(5). The most recent GLE occurred on September 2017 (6) resulting from an X-class solar flare, and it was measured on the surface of both Earth and Mars using the radiation assessment detector on the Mars Science Laboratory's Curiosity Rover.

Recently, Hubert et al. (7) proposed a GLE physical model included in a particle transport platform (ATMORAD, ATMOspheric RADiation). This platform allows for describing the extensive air shower characteristics and for assessing the ambient dose equivalent. Thus, the Galactic Cosmic Ray (GCR) is based on the Force-Field approximation model (8). The physical description of the Solar Cosmic Ray (SCR) considers the primary differential rigidity spectrum and the distribution of primary particles at the top of the atmosphere. It allows one to determine the spectral fluence rate of secondary particles induced by 
extensive showers, considering altitude range from ground to $45 \mathrm{~km}$ (9)(10)(11). Ambient dose equivalent can be determined using fluence-to-ambient dose equivalent conversion coefficients.

The objective of this paper is to analyze the GCR and SCR impacts on ambient dose equivalent considering many European flight paths. This study is limited to European flights for convenience of access to realistic plans, however, analyzes and conclusions could be applied to other areas of the world. Thus, exhaustive analyses implying solar impacts on ambient dose equivalent level can be performed, including detailed analyses considering route and airplane characteristics (departure, arrival, continent, airplane type, etc.), and the phasing of the solar event. Analyses show an important impact of the flight path, particularly the latitude which drives the cutoff rigidity variations. Moreover, dose values vary drastically during GLE

events with the route path and the phasing of the solar event. Results highlight the importance of monitoring extreme solar events and of developing semi-empirical and particle transport method to obtain reliable calculation of dose levels.

\section{MODELLING APPROACH AND VALIDATIONS}

Some methods based on semi-empirical or particle transport approaches allow one to assess the ambient dose equivalent. The challenge is to be able to evaluate the cosmic ray variations and the dose induced, while taking into account extreme solar events as GLE. This work is based on a dynamic model which integrates solar cosmic ray contribution. The benefit is to investigate fluence rates or received doses.

Fig. 1 presents the global approach. The objective is to assess the secondary spectrum to associate with the fluence to ambient dose equivalent coefficients depending on the particle type and the energy. The approach is based on a modeling platform dedicated to extrapolate the atmospheric ionizing radiation, including spectrum and secondary type and considering solar activity and extreme solar event impact. Spectra are calculated using coupled galactic and solar CR models, extensive air shower simulations and flight path generator. 


\section{A. Ambient dose equivalent assessment}

The objective is to assess the ambient dose equivalent for flights. The approach is based on three complementary parts. Firstly, it is necessary to describe the primary cosmic rays model using the force Force-Field approximation (8). Secondly, to take into account the solar event, it is necessary to characterize the solar cosmic rays using the differential rigidity spectrum and the anisotropy function reflecting the distribution of solar cosmic ray particles at the top of the atmosphere during the event. Primary and solar cosmic rays provide quantification of particle sources reaching the upper atmosphere (15)(16). The third part consists in assessing the extensive air shower using nuclear transport simulations.

\section{1) GCR model}

Some models were proposed to represent the primary GCRs. The GCR ISO model is based on a semiempirical model for which equations and parameters needed to reconstruct the models are included in the International Standard ISO 15390 (17). The CREME96 GCR (18) model is based on the model is based on the model proposed by Nymmik et al. (19) and it includes anomalous cosmic ray fluxes (visible for He, N, $\mathrm{O}$ and $\mathrm{Ne}$ around $10 \mathrm{MeV} /$ nucleon) derived from SAMPEX results. The GCR model proposed by Nymmik et al. (20) is similar to the ISO model except that at energies below $10 \mathrm{MeV} /$ nucleon the flux rises with decreasing energy.

The primary GCR is also usually modelled using the Force-Field approximation (8). This model provides a simple parametric approximation of the differential spectrum of GCR and it contains only one variable parameter named the modulation potential $\phi(t)$. The Force-Field approximation is used in this work.

\section{2) SCR model during GLE}

SCR intensity distribution observed on the Earth depends on some characteristics as the source site, the acceleration mechanism, the coronal transport, and the ejection profile as well as the transport of accelerated particles through the interplanetary magnetic field. During a typical solar event, the effect to the upper atmosphere is limited because Solar Energetic Particles (SEP) are characterized by fluxes of low energy (i.e. $<100 \mathrm{MeV}$ for protons). Analytical approximation of direct ionization can be applied 
(21)(22)(23). However, during GLE, solar proton spectra can extend up to 1-10 GeV, energies that are high enough to induce cascades of particles in the atmosphere, i.e., additional instantaneous atmospheric effects potentially affecting human activities on Earth including avionic hardware.

A physical model describing the proton spectra was proposed in a recent work (7). It is based on physical description of the differential SCR rigidity spectrum and on the anisotropy function reflecting the distribution of solar cosmic ray particles at the top of the atmosphere during the solar event, revealing information on the way these particles propagated in the interplanetary magnetic field and finally arrived in the vicinity of the Earth. This model was validated using measurements on Neutron Monitors (NM).

\section{3) Extensive Air Showers Modelling}

The incidental primary spectrum is composed by the GCR and SCR contributions. Nuclear transport methods were commonly used to assess atmospheric ionizing radiations. Thus, GEANT4 simulations of extensive air showers were performed and they allow one to generate databases which contain atmospheric radiation properties, i.e. secondary particles fluxes (neutrons, protons, electrons, muons and pions), their energies and their angular properties.

ATMORAD allows one to determine the spectral fluence rate $\delta \varphi_{n, \mu}(E) \backslash \delta E$ of secondary particles induced by extensive showers, considering an altitude range from ground to $45 \mathrm{~km}$, taking into account the GCR and SCR spectra and the magnetic field impact.

\section{4) Dose assessment}

Fluence to ambient dose equivalent conversion coefficients $f_{H^{*}}$ are known for most particles of interest and in the energy ranges related to atmospheric radiations (24)(25)(26)(27) (28)(29). The ambient dose equivalent can be assessed by coupling these coefficients with the spectral fluence rate of secondary particles, and by considering a given flight route defined by its characteristics (latitudes, longitudes and altitudes). 


\section{B. Flight path database representative to European international air traffic}

Flight path database representative to European international air traffic was considered in this work. Flight trajectories are based on the Eurocontrol Demand Data Repository (DDR (12)) and consider realistic flight plans with and without regulations or updated with Radar Data from CFMU (Central Flow Management Unit). Thus, the DDR was used to access to realistic flights operated during a complete week, considering fights departing from, landing to or crossing Europe. These trajectories are available in different states: 1) M1: from Flight Plan, 2) M2: M1 with regulations and 3) M3: Flight Plan updated with CFMU. The M3 data has been used here, in order to take into account the regulation actions and the air traffic control orders. Each path was characterized by geophysical locations (timing, longitude, latitude and altitude), airplane type, city of departure and arrival. This primary database contains around 120,000 flight paths and characteristics, representative of the European international air traffic during one typical week. The database structure implies that the relative frequency of each route is respected, then it provides high statistic according to the aeronautical activities. Fig. 2 presents a world map indicating selected flights contained in the flight database.

High density is observed in Europe, North America and Southeast Asia. Geographical areas like Antarctica or Oceania are not represented in the database, because there is no direct flight between Europe and these world regions. Other territories are characterized by lower densities, such as Africa, North Asia (Siberia) and South America, which is explained by lower aeronautical activities and by the fact that most flights between Europe and these regions are not direct. Considering the previous descriptions, the ambient dose equivalent $H^{*}$ for a given flight thanks to the equation 1 :

$$
H^{*}=\sum_{i=n, p, \mu, e} \int_{p a t h} \int_{E} \frac{\partial \varphi_{i}(E, t)}{\partial E} f_{i}^{H^{*}}(E) \delta E \delta_{p a t h}
$$




\section{VALIDATION BASED ON FLIGHT AND COSMIC RAY MEASUREMENTS}

\section{A. Quiet solar period}

Comparisons with standard approaches and measurements were presented in previous works (7), including direct radiation fields and ambient dose equivalent assessments. Especially, ambient dose equivalents are considered for selected flights operated in January 2018 where measurements are available during quiet solar activity conditions. Fig. 3 presents the ambient dose equivalents measured and calculated for flights departing from or arriving to London, and connected with destinations distributed in North America (Los Angeles), Asia (Tokyo) or Africa (Johannesburg).

Calculated ambient dose equivalents are relevant with measurements. Standard deviations associated to calculations and measurements have different origins. Indeed, standard deviations represent the impact induced by the route diversity and by the scientific instrument for calculations and measurements, respectively. These results can be compared with other measurements and calculations which can reveal somewhat different levels of values. Thus, a considerable work is still needed for model/observation crosscomparisons to understand the differences, implying probably airborne measurement campaigns.

\section{B. Extreme solar events}

Two GLE events were considered in this part. Firstly, the GLE which occurred on 23 February 1956 (GLE \#5) was investigated because it constitutes a reference as the most intense proton event observed since 1942. Secondly, the event occurring on 20 January 2005 as the most recent large intensity GLE with the advantage of having being monitored on a large number of NMs (30)(31)(32).

Fig. 4(a) presents the calculated and the measured cosmic ray variation observed during GLE \#5 and \#69, and for some selected locations. Calculated and measured CR variations concern distant stations and relevance demonstrate the ability to model the anisotropy properties of GLEs. Concerning specifically the GLE \#5, profiles of CR variations show that the maximum amplitude was obtained by the Leeds NM i.e. a CR increase of $4500 \%$ of the cosmic ray level. Moreover, calculations overestimate the measured 
variations by a factor of 20-30 \% for NMs operated in Leeds, Stockholm and Chicago, while cosmic ray variation calculated in Ottawa are highly underestimated $(\sim 40 \%)$. Variations are quite correct for the first three stations, whereas a significant difference is observed for Ottawa.

In previous works (13)(14), potential exposures measured on airplane on different routes during GLE \#5 were proposed. The evaluated dose value is around $1.5 \mathrm{mSv}$ for flights from Paris to Washington. The Fig. 4(b) presents normalized distributions of ambient dose equivalent calculated for the GLE \#5. Orders of magnitude of ambient dose equivalent are from 900 to $1800 \mu \mathrm{Sv}$, depending to the path characteristics. These results confer a satisfactory confidence level for calculating ambient dose equivalent, and especially in taking into account the GLE dynamics.

\section{STATISTICAL ANALYSES OF AMBIENT DOSE EQUIVALENT DURING QUIET SOLAR CONDITIONS}

The objective is to assess the ambient dose equivalent during a quiet solar period and for each flight path described in the European air traffic database. The solar activity is considered as quiet with a value of solar potential of $700 \mathrm{MV}$ which corresponds to the current level during the month of January 2018. These results can be statistically analyzed considering some parameters as the departure/arrival continent or city, altitude or latitude criterion.

Fig. 5 presents the normalized distributions distinguishing flight on departure/arrival, i.e. from Europe to Europe, Africa, North America, South America and Asia (and reciprocally from any continent to Europe). The overall analysis of results indicates that the ambient dose equivalent ranges are from low level to around $80 \mu \mathrm{Sv}$. Results show that flights to or from Africa and Europe cover ambient dose equivalent ranging from low dose (low distance and altitude) to levels of $20 \mu \mathrm{Sv}$. In the case of observed ambient doses for flights involving South America, the distance between the continent and Europe induces longer flight times and equatorial/tropical latitudes. The conjugation of these two properties induces ambient dose equivalent levels from 8 and $25 \mu \mathrm{Sv}$. Flights involving Asia are characterized by a high diversity. There are indeed very short flights (for example Asia Minor) inducing a low ambient dose equivalent level, and there are long-distance flights characterized by very northern routes (for example, the Siberian route for Japan). 
It implies dose levels which can go up to $80 \mu \mathrm{Sv}$, i.e. the maximum dose observed in the global distribution. Concerning the transatlantic flights, i.e. from Europe to North America and reciprocally, ambient dose equivalent level are from 15 to $80 \mu \mathrm{Sv}$. Low ambient doses are obtained for the southern cities of the East Coast of the United States (Miami, Orlando, Atlanta ...), while medium dose are found for the northern cities (New-York, Boston...). High ambient dose equivalents concern the long routes as Los Angeles or San-Francisco. Ambient doses are then of the order of $80 \mu \mathrm{Sv}$.

Fig. 6 presents ambient dose equivalent world maps derived from calculations. The absolute dose value world map is proposed in Fig. 6 (a) while this ambient dose rate world map in $\mu \mathrm{Sv} / \mathrm{hr}$ is presented in Fig. 6(b). The color scale refers to the dose level (from low to $80 \mu \mathrm{Sv}$ ) or the dose rate (from 1 to $8 \mu \mathrm{Sv} / \mathrm{hr}$ ), and each flight is positioned according to the arrival or departure city (European city being the reference). Low data densities are observed in geographical regions where direct traffic with Europe is reduced (South America, Africa and some part of Asia). The dose world map illustrates that most affected destinations in terms of dose are East Asia and Northwest America. The main parameter is the duration (or the flight distance), however the latitude is a significant parameter. This is very well illustrated by the difference observed between the South America and the North America (similar duration but significant difference on the dose level).

The world map considering the ambient dose rate presented in Fig. 6(b) has the advantage to take into account the impact of the flight distance/duration. Thus, flights crossing high latitudes (North America and Europe since studies focus on European-air-traffic) are the more problematic, due to the low geomagnetic cutoff rigidity. For equivalent latitudes in Europe, the risk seems to be lower. This is due to the fact that the Europe - Europe paths are fairly straightforward while those linking Europe to North Asia and North America pass through high latitudes Atlantic or Siberian highways. Conversely, equatorial and tropical regions are characterized by low ambient dose rate. A nuance could be made concerning the most Southern destinations in South America (very high absolute latitude), however, the overall dose rate does not reflect the fact that the instantaneous dose level is higher at the end or at the beginning of the flight. 


\section{STATISTICAL ANALYSES OF AMBIENT DOSE EQUIVALENT DURING EXTREME SOLAR EVENT}

The GLE model was applied during extreme events occurring on the 23 February 1956 (\#5) and the 20 January 2005 (\#69), respectively. Besides the differential SCR rigidity spectrum and due to the anisotropy characteristics, the ambient dose equivalent depends on the dynamic. Contrary to the Forbush decrease (FD), GLE are prompt events which complicate the dose assessment. Indeed, dose values vary drastically with the route profile but also with the phasing of the solar event.

\section{A. Statistical analyses applied to selected flights}

Five flights were selected considering high statistical path number issued from Flight Plan updated with Radar Data (CFMU, M3). To consider continents or sub-continents representative of European international air traffic, flights linking Paris to Los Angeles, New York, Tokyo, Johannesburg and Sao Paulo city are investigated, and several hundred trajectories are considered for each of these flights. Fig. 7 presents a world mapping describing these flights. There is a great diversity of trajectories for a given flight; it is especially true for Los Angeles, New York and Tokyo city. Some anomalies are identifiable on the trajectory, which reflects flight plan modifications probably due to weather conditions. In the specific case of Paris - Tokyo flights, it is possible to distinguish flights using a Siberian route and flights using a low latitude route. A fairly similar remark can be made about Paris - Los Angeles flights.

Fig. 8 presents normalized distribution distributions of the ambient dose equivalent during quiet solar activity (i.e. solar modulation of $700 \mathrm{MV}$ ) and for the five selected flights. Fig. 8(a) concerns flights from Paris and Fig. 8(b) flights to Paris. This distinction is important because the flight durations are not the same due to the prevailing atmospheric currents (East - West), and the air corridors (in the point of view of latitude and/or altitude). This is illustrated by the results obtained for flights Paris - Los Angeles. Indeed, normalized distribution distributions are from 45 to $70 \mu \mathrm{Sv}$ for the East-West (EW) direction, while the range is from 30 to $60 \mu \mathrm{Sv}$ for the West-Est (WE) direction. In term of average value, ambient dose equivalents are 59 and $51 \mu \mathrm{Sv}$ for the EW and WE direction, respectively. This difference is even more significant for Paris - Tokyo flights, with average values of 54 and $65 \mu \mathrm{Sv}$. Analyses of distributions 
obtained from Paris - Johannesburg flights and to a lesser extent Paris Sao Paulo flights, show that NorthSouth flights are relatively unaffected by the flight direction.

Same analyses were performed considering the GLE \#69 occured 4 hours after the departure of flights (Fig. 9). It is interesting to note a significant impact of direction in ambient dose distributions for Paris Los Angeles. To a lesser extent, it's also noticeable for Paris - New York and Paris - Tokyo flights. This confirms the interest of accurately taking into account the dynamics of GLE in the dose assessment.

For Paris - Tokyo flights, normalized distributions are from 50 to $280 \mu \mathrm{Sv}$ for the East-West (EW) direction, while the range is from 125 to $360 \mu \mathrm{Sv}$ for the West-Est (WE) direction. In other words, there may be a factor up to 5 on the ambient dose level induced by the path. Comparison of Fig. 8(b) and Fig. 9(b) show that some paths are weakly sensitive to the impact of the GLE. This suggests that during extreme events, it should be possible to reroute the airplane to avoid the radiation impacts. However, in the case of GLEs for which the solar particles are quasi-relativistic, it is not easy to anticipate this problematic for current air traffic. Conversely, it is possible to issue recommendations to avoid certain geographic regions or latitudes

In the specific case of Paris - Johannesburg and Paris - Sao Paulo flights, the GLE impact on ambient dose levels is relatively limited, with an increase of up to $20 \%$. This is primarily an effect of latitude since these routes cross the tropical and equatorial latitudes.

Table I presents the average value of ambient dose equivalent calculated on selected flights, using realistic sampling of routes and considering the both GLE. Ambient dose equivalents obtained during quiet period is also presented (solar modulation of $700 \mathrm{MV}$ ). The first analysis concerns the average ambient dose equivalent obtained during quiet solar activity. Despite the directions of the flight route, results are quite homogeneous for certain flights. For example Paris to Sao Paulo for which the dose is in the order of $17 \mu \mathrm{Sv}$. The main reason is that the departure and the arrival latitudes are quite similar. This is a finding that mainly concerns North-South routes because they undergo the same atmospheric currents. In all other cases, differences are observed in the average values. The route analysis confirms that air corridors and 
altitudes are mapped according to the direction of flight, which is a consequence of air regulations.

Focusing on the results obtained with GLEs, a very large asymmetry is observed for some flight routes, the most spectacular example concerning Los Angeles and Tokyo flights. Indeed, considering Paris Tokyo flights and GLE \#5, the average ambient dose equivalent values are 1146 and $420 \mu \mathrm{Sv}$ in the WE and EW directions, respectively. Moreover, results confirm that North-South routes are characterized by a relatively low dissymmetry, even during a GLE.

The GLE can be characterized by a high anisotropy (Fig. 4) had shown that CR variations during GLE \#69 are of 200 and $3000 \%$ for the Thule and the Mc Murdo stations, respectively). An interesting perspective consists in modifying the anisotropy characteristics and to investigate their impacts on ambient dose equivalent assessment. Preliminarily analyses were presented in previous work (7), proposing a GLE based on the spectrum and dynamics of GLE \#69, but reversing the North-South anisotropy properties. Finally, these results demonstrate the importance of physically describing the spectral properties, dynamics and anisotropy of a GLE.

\section{B. Exhaustive statistical analyses}

As previously identified, the dose is highly dependent on the flight route profile and the GLE dynamic. These parameters explain the observed differences according to the direction of the flight, and differences observed from one continent to another.

Fig. 10 presents the normalized ambient dose equivalent distributions considering the quiet solar period, the GLE \#5 and the GLE \#69. A delay of 4 hours between departure and GLE occurrence was considered for the both GLE scenarios. Fig. 10(a) considers all flights recorded in the European flight database, while the Fig. 10(b) analyses the flight between Europe to North America and reciprocally. A shift of the distribution is observed towards higher levels of ambient dose equivalent, i.e. of the order of hundred $\mu \mathrm{Sv}$ for the GLE \#69 and of thousands $\mu$ Sv for the GLE \#5. It is interesting to focus on transatlantic flights because they require fairly high latitudes. While some flights appear to be relatively unaffected by the GLE, a more detailed analysis indicates that these flights are arriving to or departing from airports in the 
Southern United States or from Mexico. However, the majority of flights are impacted by GLE, by a factor of up to 5 and 25 for the GLE \#69 and \#5, respectively.

Results obtained for South America and Asia are presented in Fig. 11(a) and Fig. 11(b), respectively. The impact of GLE \#69 and \#5 is very low for South American flights, which is mainly due to flight latitudes (i.e. equatorial and tropical). The geomagnetic cutoff rigidity in these geographical areas is high (i.e. between 8 to $12 \mathrm{GV}$ ) and strongly reduces the penetration of additional solar cosmic rays. In the case of Asian flights, there is some similarity with the orders of magnitude observed for North America. Moreover, flights data presented in the Table 1 give some examples and comparisons.

\section{Impact of the GLE time occurrence}

The time defining the GLE occurrence has an importance in the assessment of the ambient dose equivalent. Two Paris - Los Angeles flights were selected to investigate the impact of GLE occurrence time, the first one being the lowest dose (quiet period), while the second induced the highest dose. Fig. 12(a) presents latitude dynamics of flights \#5 and \#23. The route \#23 crosses latitude of $75^{\circ}$ while the second does not reach $55^{\circ}$. Moreover, it is important to specify that altitude dynamics are quite similar as well as flight duration (11.7 km and $11 \mathrm{~h}$, respectively)

Then, Fig. 12(b) and Fig. 12(c) show estimates for the total dose rate profiles (in $\mu \mathrm{S} / \mathrm{h}$ ) during both flights and considering the GLE \#69 scenario occurring later the flight departure. The delay of the GLE occurrence varies from 0 to $11 \mathrm{~h}$. A significant difference is observed between these flights, whatever the delay. It is obvious that this difference is the consequence of the flight latitude. Besides, it is very interesting to note that dose rates are similar when latitudes are quite similar (case of delays of 0 and 10). A factor of 1.5 is observed by comparison of dose rate amplitudes of flights (considering the same delay). Finally, this analysis shows that according to the dynamic phasing of the GLE and according to the path characteristics, the dose rate can vary up to a factor 10 , involving significant variations of the total ambient dose equivalent. It is therefore difficult to assert the dose level induced by a GLE without considering a physical and dynamic description. 
The total ambient dose equivalents as function of the delay are presented in Fig. 12(d) for the both flights. The ratios between the two flights range from a factor of 1.2 to a factor of 2 . For delays of 9 or more, there is no difference in the total ambient dose equivalent, which may be directly related to the flight latitude (typically inferior to $45^{\circ}$ ) for which the GLE has a non-significant effect.

Fig. 13 and Fig. 14 present the normalized distributions of the ambient dose equivalent for flights Europe - North America and considering several delays between the flight departure and GLE occurrence, 2, 4 and 6 hours. Results are obtained for the GLE \#69 and \#5 in Fig. 13 and Fig. 14, respectively. It is obvious that the impact of the occurrence time is more significant during the GLE \#69. It is probably due to the anisotropy properties which are particularly asymmetric for this event. In the case of GLE \#5, solar cosmic rays are relatively homogenous and the main parameters are the altitude and the latitude. This issue is confirmed by the analysis of the results obtained considered the modified GLE \#69.

\section{DISCUSSIONS}

In the point of view of dose risk and assessment, several international agencies have established recommended dose limits for both workers and general public for different types of activities. It is on these bases that national or continental regulations are established. For example, according for the International Commission on Radiological Protection (ICRP), recommendations for annual effective dose are $20 \mathrm{mSv}$ and $1 \mathrm{mSv}$ averaged over a five year period for aircrews and for the public, respectively. Furthermore, it is recommended that the effective dose does not exceed $50 \mathrm{mSv}$ in a single year, barring special circumstances. The effective dose is convenient to assess the biological risk to radiation, however it is not a measurable quantity and the ambient dose equivalent is used for operational purpose. In general the ambient dose equivalent slightly overestimates the effective dose, and it is not a conservative assessment at aviation altitudes, specifically in high rigidity regions. Nevertheless, it is regarded as an acceptable approximation for effective dose at aircraft altitudes (32)(33).

There are a number of methods that can be used for the post or real-time evaluation of dose for operational purposes $(34)(35)(36)(37)(38)$. These methods are relevant to evaluate the dose induced by the 
galactic cosmic ray contribution, i.e. during quiet solar period. Other approaches (39), propose to predict real-time atmospheric exposure from GCR and solar energetic particle (SEP) events. The SEP spectrum is derived using ion flux measurements taken from the NOAA/GOES and NASA/ACE satellites. The methodology used in this work is not intended to propose an alternative to these methods, but to investigate in detail the impact of a dynamic model of extreme solar event.

Results presented in this work show that the extra ambient dose equivalent for flights during extreme GLEs can be from a few hundred to a few thousand $\mu$ SV. However, the dose level depends on several physical parameters, i.e. the differential SCR rigidity spectrum, the anisotropy function reflecting the distribution of SCR particles at the top of the atmosphere during the solar event, and their dynamics. Dose levels for flights are much higher, most likely in the range of allowable levels. The orders of magnitude of dose levels induced during extreme solar events raise a number of issues, both for the public, for aircrews and for avionics hardware. In the specific case of public aeronautical usages, the increase of the annual Passenger numbers and the individual increase of cumulative flights (mainly business travel) require improvement of the dose assessment (recommendations for annual effective dose of $1 \mathrm{mSv}$ over a five year period). This point highlights the importance of monitoring these solar events and of developing semiempirical and particle transport method to obtain reliable calculation of dose levels. Another requirement is the improvement of the alert system and the recommendation diagnostic.

\section{CONCLUSION}

To investigate the ambient dose equivalent during quiet solar activity and extreme solar events (GLE \#5 and \#69), realistic flights operated during a complete week were considered. This database contains flights departing from, landing to or crossing Europe. Relevant validations were presented for ambient dose equivalent during quiet solar activity, then, comic ray variations and flight dose assessments during GLEs.

Statistical analyses show that ambient dose equivalents vary drastically, on the one hand with the route path (latitude, longitude and altitude), on the other hand with the phasing of the solar event. Indeed, GLE are prompt events which complicate the dose assessment. The combination of high dose rates and a prompt 
dynamics induce dose levels of about a few hundred $\mu \mathrm{Sv}$ and a few thousand $\mu \mathrm{Sv}$ for the GLE \#69 and \#5, respectively. Results show that contrarily to the classical solar flare inducing FDs or classical GLEs, severe GLEs can induce much larger dose levels. Then, for most GLEs that are not severe, the additional dose is minor compared to the typical annual effective dose. Concerning severe events, additional doses impact significantly the annual effective dose. This point highlights the importance of monitoring these solar events and of developing semi-empirical and particle transport methods to obtain reliable calculation of dose levels.

\section{REFERENCES}

(1) P. Lantos and N. Fuller, "History of the solar Flare radiation doses on-board aircraft using a semi-empirical model and concorde measurements", Radiat Prot Dosim, vol. 104, 2003, pp. 199-210.

(2) J. A. Van Allen and J. R. Winckler, "Spectrum of low-rigidity cosmic rays during the solar flare of February 23 1956”, Phys. Rev., vol. 106 1957, pp. 1072-1073.

(3) D. F. Smart and M. A. Shea, "Probable pitch angle distribution and spectra of the 23 February 1956 solar cosmic ray event”, Proc. 21st Int. Cosmic Ray Conf, vol. 5, 1990, pp. 257-260.

(4) The 1990 recommendations of the International Commission on Radiological Protection (ICRP), publication 60. Ann. ICRP 21, 1991.

(5) The 2007 recommendations of the International Commission on Radiological Protection (ICRP), publication 103. Ann. ICRP 37, 2007.

(6) G. Hubert, M. Piazanotto and C. Federico, "Spectral analyses of Cosmic-Ray-induced neutron during the Forbush Decreases and the Ground Level Enhancement of September 2017 solar event", submitted to Astrophysical Journal, 2018.

(7) G. Hubert and S. Aubry, "Atmospheric cosmic ray variation and ambient dose equivalent assessments considering Ground Level Enhancement thanks to coupled anisotropic solar cosmic ray and extensive air shower modeling”, Radiation Research, vol. 188, issue 5, 2017, pp. 517-531.

(8) L. Gleeson and W. Axford, "Solar Modulation of Galactic Cosmic Rays", Astrophysical Journal, vol. 154, 1968 pp. 1011. 
(9) G. Hubert and A. Cheminet, "Radiation effects investigations based on atmospheric radiation model (ATMORAD) considering GEANT4 simulations of extensive air showers and solar modulation potential", Radiation Research, vol. 184, issue 1, 2015, pp. 83-94.

(10) G. Hubert, C. Federico, M. Pazianotto, O. Gonzales, "Long and short-term atmospheric radiation analyses based on coupled measurements at high altitude remote stations and extensive air shower modelling", Astroparticle Physics Journal, vol. 74, 2016, pp. 27-36.

(11) G. Hubert, "Analyses of cosmic ray induced-neutron based on spectrometers operated simultaneously at midlatitude and Antarctica high-altitude stations during quiet solar activity”, Astroparticle Physics Journal, vol. 83, 2016, pp.30-39.

(12) Euricontrol Demand Data Repository, www.eurocontrol.int

(13) P. Lantos, "Radiation doses potentially received on-board aeroplanes during recent solar particle events". Radiation Protection Dosimetry, vol. 118, issue 4, 2006, pp. 363-374.

(14) P. Lantos and N. fuller, "Semi-empirical model to calculate potential radition exposure on board airplane during solar particle events”, IEEE trans On Plasma Sci., vol. 32, issue 4, 2004, pp. 1468-1477.

(15) D. Band, J. Matteson, L. Ford, B. Schaefer, D. Palmer, B. Teegarden et al., "BATSE observations of gammaray burst spectra. I - Spectral diversity”, Astrophysical Journal, vol. 413, 1993, pp. 281-292.

(16) C. Plainaki, A. Belov, E. Eroshenko, H. Mavromichalaki, V. Yanke, "Modeling ground level enhancements: Event of 20 January 2005”, Journal of Geophysical Research, vol. 112, 2007, A04102.

(17) ISO-15390, Space environment (natural and artificial) - Galactic cosmic ray model

(18) Tylka, A.J., Dietrich, W.F. and Boberg, P.R., Probability Distributions of High-Energy Solar-Heavy-Ion Fluxes from IMP-8: 1973-1996, IEEE Trans. on Nucl. Sci., 44, 2140-2149 (1997).

(19) Nymmik, R.A., Panasyuk, M.I., Pervaja, T. I. and Suslov, A.A., A Model of Galactic Cosmic Ray Fluxes, Nucl. Tracks \& Radiat. Meas, 20, 427-429 (1992).

(20) Nymmik, R.A., Panasyuk, M.I. and Suslov, A.A., Galactic cosmic ray flux simulation and prediction: Adv. Space Res., Vol. 17, No. 2, 1996. 
(21) F. M. Vitt, C. H. Jackman, "A comparison of sources of odd nitrogen production from 1974 through 1993 in the Earth's middle atmosphere as calculated using a two-dimensional model", Journal of Geophysical Research, vol. 101, 1996, pp. 6729-6740.

(22) A. Krivolutsky, A. Kuminov, A. Kukoleva, A. Repnev, N. Pereyaslova, M. Nazarova, "Solar proton activity during cycle 23 and changes in the ozonosphere: Numerical simulation and analysis of observational data", Geomagn Aeronom, vol. 48, 2008, pp. 432-445.

(23) P. Verronen, B. Funke, M. L'opez-Puertas, G. Stiller, T. Clarmann et al. "About the increase of HNO3 in the stratopause region during the Halloween 2003 solar proton event”, Journal of Geophysical Research Letter, vol. 35, 2008, L20809.

(24) M. Pelliccioni, "Overview of Fluence-to-Effective Dose and Fluence-to-Ambient Dose Equivalent Conversion Coefficients for High Energy Radiation Calculated Using the FLUKA Code", Radiat Prot Dosimetry, vol. 88, issue 4, 2000, pp. 279-297.

(25) A. Ferrari, M. Pelliccioni, M. Pillon, "Fluence to Effective Dose Conversion Coefficients for Muons", Radiat. Prot. Dosimetry, vol. 74, 1997, pp.227-233.

(26) A. Ferrari, M. Pelliccioni, M. Pillon, "Fluence to Effective Dose and Effective Dose Equivalent Conversion Coefficients for Protons from $5 \mathrm{MeV}$ to $10 \mathrm{GeV}$ ", Radiat Prot Dosimetry, vol. 71, issue 2, 1997; pp. 85-91.

(27) A. Ferrari, M. Pelliccioni, M. Pillon, "Fluence to Effective Dose and Effective Dose Equivalent Conversion Coefficients for Electrons from $5 \mathrm{MeV}$ to $10 \mathrm{GeV}$ ”, Radiat Prot Dosimetry, vol. 71, issue 2, 1997, pp.97-104.

(28) T. Sato, A. Endo, M. Zankl, N. Petoussi-Hens, K. Niita, "Fluence-to-dose conversion coefficients for neutrons and protons calculated using the PHITS code and ICRP/ICRU adult reference for computational phantoms", Physics in Medicine and Biology, vol. 54, 2007, pp. 1997-2014.

(29) T. Sato, A. Endo, K. Niita, "Fluence-to-Dose Conversion Coefficients for Muons and Pions Calculated Based on ICRP Publication 103 Using the PHITS Code”, Progress in Nuclear Science and Technology, vol. 2, 2011, pp. $432-436$.

(30) H. Miayasaka, E. Takahashi, S. Shimoda, Y. Yamada, I. Kondo et al., "The solar Event of 20 January 2005 observed with the Tibet YBJ Neutron Monitor Observatory”, 29th International Cosmic Ray Conference Pune, vol. 1, 2005, pp. 241-244. 
(31) I. Usoskin, A. Tylka, G. Kovaltsov and W. Dietrich, "Ionization effect of strong solar particle events: Lowmiddle atmosphere", Proceedings of the 31st ICRC, 2009.

(32) Meier, M., M. Hubiak, D. Matthiä, M. Wirtz, and G. Reitz. Dosimetry at aviation altitudes (2006-2008). Radiat. Prot. Dosim., 136 (4), 1-35, 2009, DOI: 10.1093/rpd/ncp142.

(33) Mertens, C., M. Meier, S. Brown, R. Norman, and X. Xu. NAIRAS aircraft radiation model development, dose climatology, and initial validation. Space Weather, 11 (10), 603-635, 2013, DOI: 10.1002/swe.20100.

(34) P. Meyer, E. Parker, J. Simpson, "Solar cosmic rays of February 1956 and their propagation through interplanetary space", Phys Rev, vol. 104, issue 3, 1956, pp. 768-783.

(35) Anderson JL, Mertens CJ, Grajewski B, Luo L, Tseng CY, Cassinelli RT. Flight attendant radiation dose from solar particle events. Aviat Space Environ Med 2014 Aug; 85(8):828-32.

(36) Schraube H, Leuthold G, Heinrich W, Roesler S, Mares V, Schraube G. EPCARD - European program package for the calculation of aviation route doses. User's manual. GSF-National Research Center, Neuherberg, Germany (2002). ISSN 0721-1694. GSF-Report 08/02.

(37) Clairand I, Fuller N, Bottollier-Depois JF, Trompier F. The SIEVERT system for aircrew dosimetry. Radiat Prot Dosim 2009; 136(4):282-285.

(38) Latocha M., Beck P., Rollet S., AVIDOS--a software package for European accredited aviation dosimetry. Radiat Prot Dosimetry. 2009 Oct;136(4):286-90.

(39) Mertens, C. J., W. K. Tobiska, D. Bouwer, B. T. Kress, M. Wiltberger, S. C. Solomon, and J. J. Murray, Development of the Nowcast of Atmospheric Ionizing Radiation for Aviation Safety (NAIRAS) model, AIAA 2009-3633-978, 2009. 
IX. TABLES

TABLE I: AVERAgE VALUE OF AmbIENT DOSE EQUiVALENT ( $\mu \mathrm{Sv}$ ) OBTAINED FOR SELECTED FLIGHTS, CONSIDERING THE QUIET PERIOD, GLE \#69 AND \#5 OCCURRING 4 HOURS LATER DEPARTURE.

\begin{tabular}{llll}
\hline Departure $\rightarrow$ arrival & Quiet & GLE \#69 & GLE \#5 \\
\hline Paris $\rightarrow$ Los Angeles & $58.7 \pm 4.3$ & $220.7 \pm 19.7$ & $1713 \pm 157$ \\
Los Angeles $\rightarrow$ Paris & $51.1 \pm 5.1$ & $106.5 \pm 21.1$ & $619 \pm 181$ \\
Paris $\rightarrow$ New York & $36.3 \pm 5.5$ & $105.9 \pm 19.9$ & $690 \pm 122$ \\
New York $\rightarrow$ Paris & $26.6 \pm 2.7$ & $89.3 \pm 15.2$ & $538 \pm 89$ \\
Paris $\rightarrow$ Tokyo & $53.9 \pm 5.0$ & $233.0 \pm 15.3$ & $1146 \pm 68$ \\
Tokyo $\rightarrow$ Paris & $64.7 \pm 3.9$ & $175.7 \pm 11.7$ & $420 \pm 27$ \\
Paris $\rightarrow$ Johannesburg & $15.8 \pm 1.2$ & $17.2 \pm 1.4$ & $26.5 \pm 2.1$ \\
Johannesburg $\rightarrow$ Paris & $22.8 \pm 1.5$ & $23.7 \pm 1.5$ & $25.2 \pm 1.6$ \\
Paris $\rightarrow$ Sao Paulo & $17.2 \pm 1.7$ & $18.7 \pm 1.8$ & $24.6 \pm 2.3$ \\
Sao Paulo $\rightarrow$ Paris & $17.4 \pm 1.6$ & $19.4 \pm 1.7$ & $27.8 \pm 2.1$ \\
\hline
\end{tabular}


X. Figures

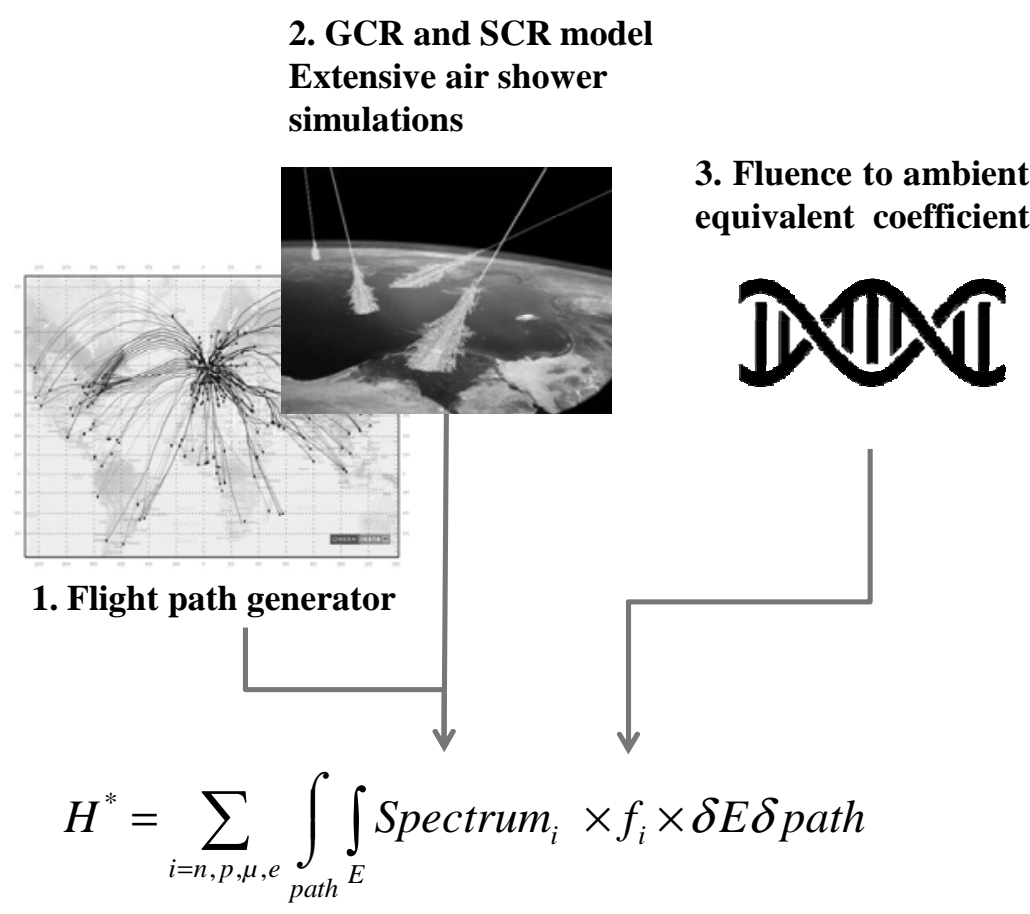

Fig. 1. Overview of the methodology based on the flight path generator, the GCR/SCR models, the extensive air shower modelling, and fluence to ambient dose equivalent coefficient. 


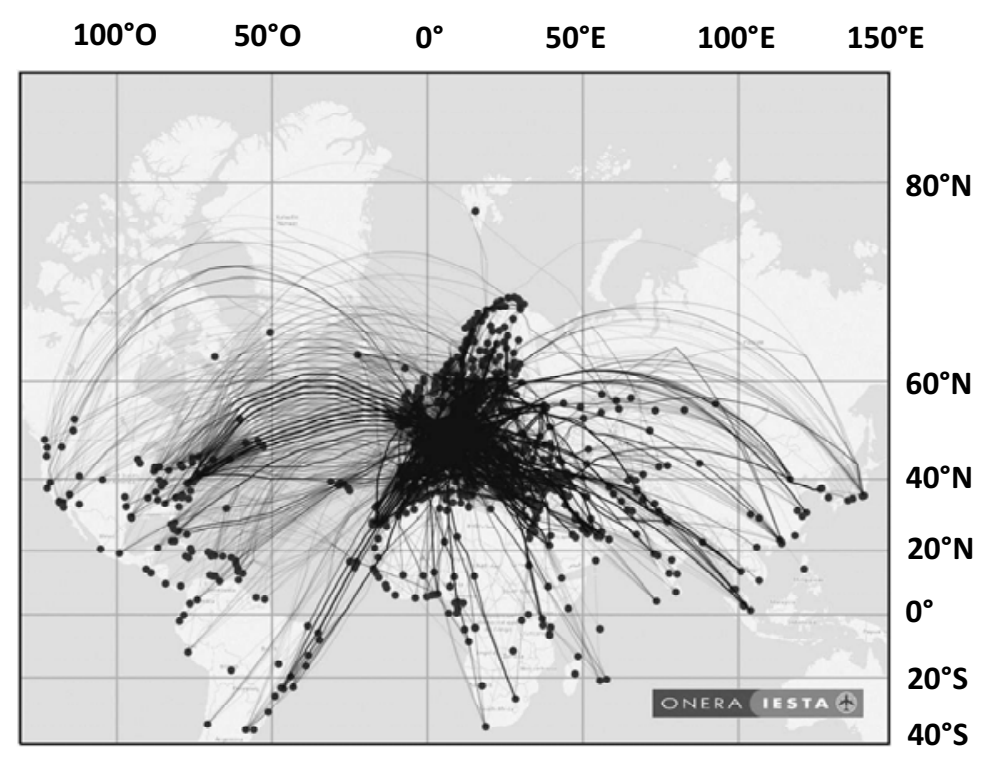

Fig. 2. World map of arrival/departure airports representative to the European international air traffic. Flight paths are issued from the Eurocontrol Demand Data Repository, allowing to access to realistic flights (timing, latitude, longitude and altitude).

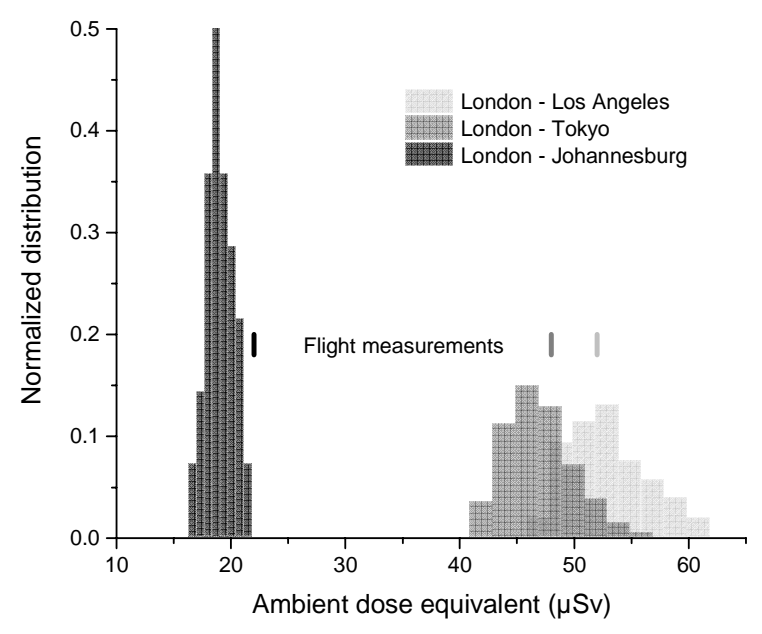

Fig. 3. Ambient dose equivalent in $\mu S v$, obtained by calculations (ATMORAD) and issued from measurements presented in Bentley et al. Three flights were considered, from London to Los Angeles, Tokyo and Johannesburg. 

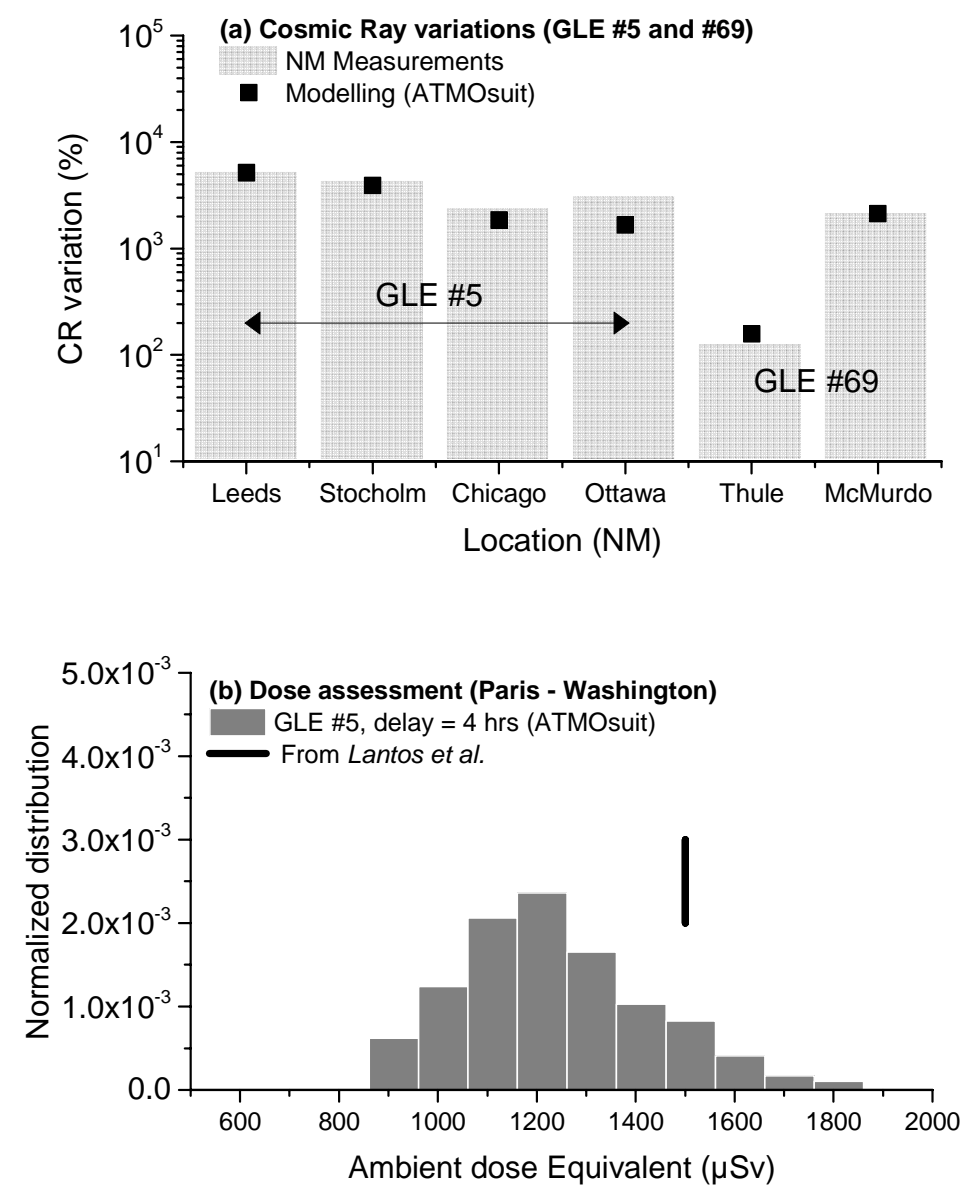

Fig. 4. (a) Maximum cosmic ray variation measured during GLE \#5 and \#69 and comparison with calculations issued from ATMORAD. (b) Dose assessments for Paris-Washington flights (supersonic), issued from calculations and from previous works (Lantos et al.). 

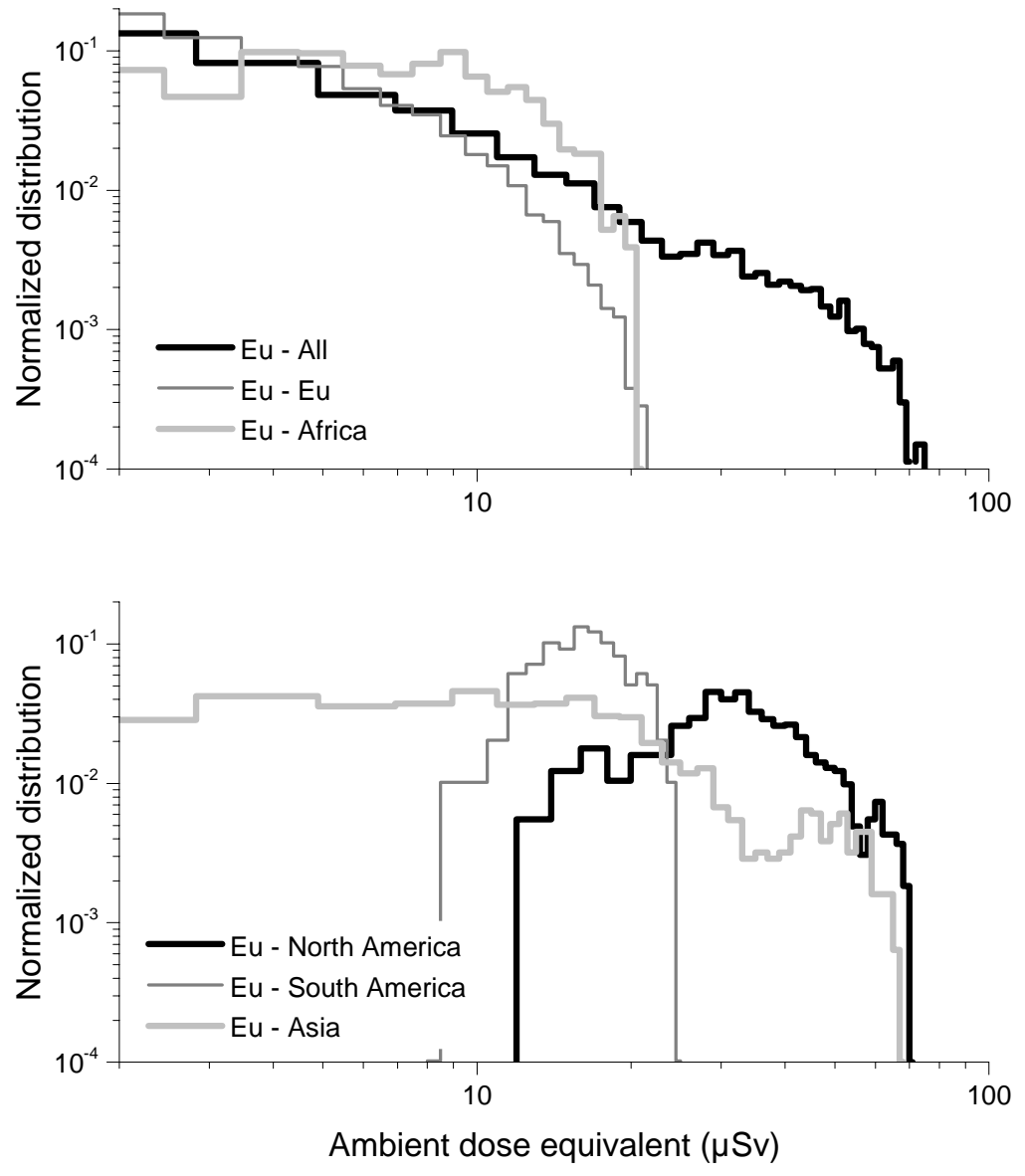

Fig. 5. Normalized distribution of the ambient dose equivalent considering flight database representative to European international air traffic. Results obtained for all flights, and from Europe to Europe, Africa, North America, South America and Asia. 
(a) Ambient dose equivalent ( $\mu \mathrm{Sv})$
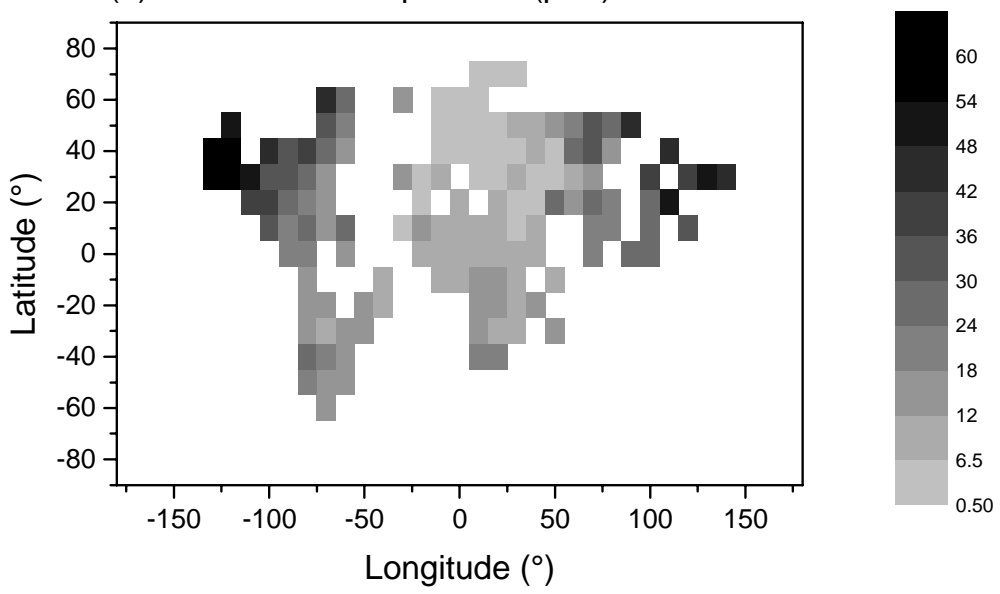

(b) Ambient dose equivalent rate $(\mu \mathrm{Sv} / \mathrm{hr})$

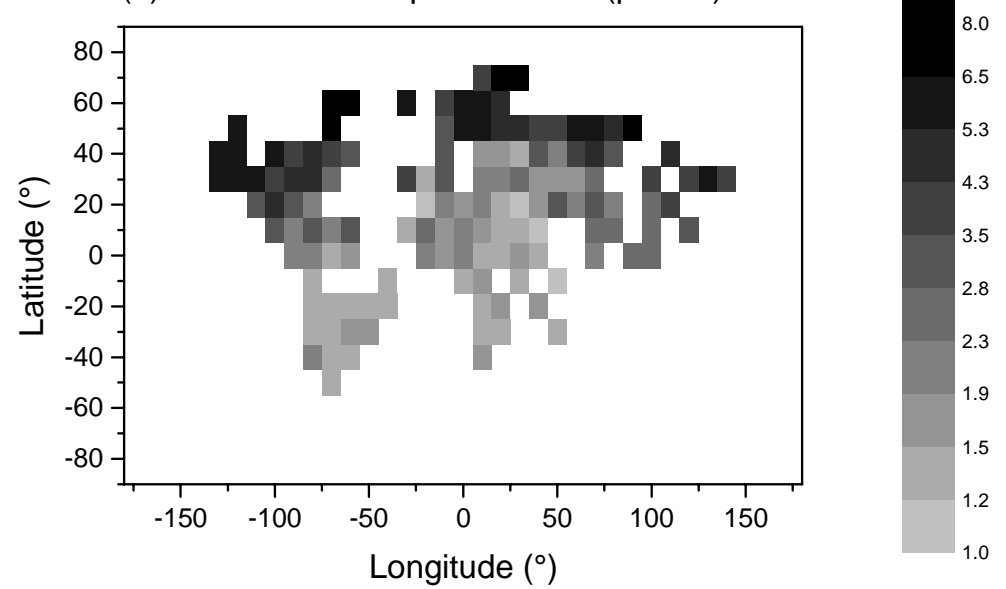

Fig. 6. Ambient dose equivalent (a) and ambient dose equivalent rate (b) world maps derived from calculations applied to representative European international air traffic. 


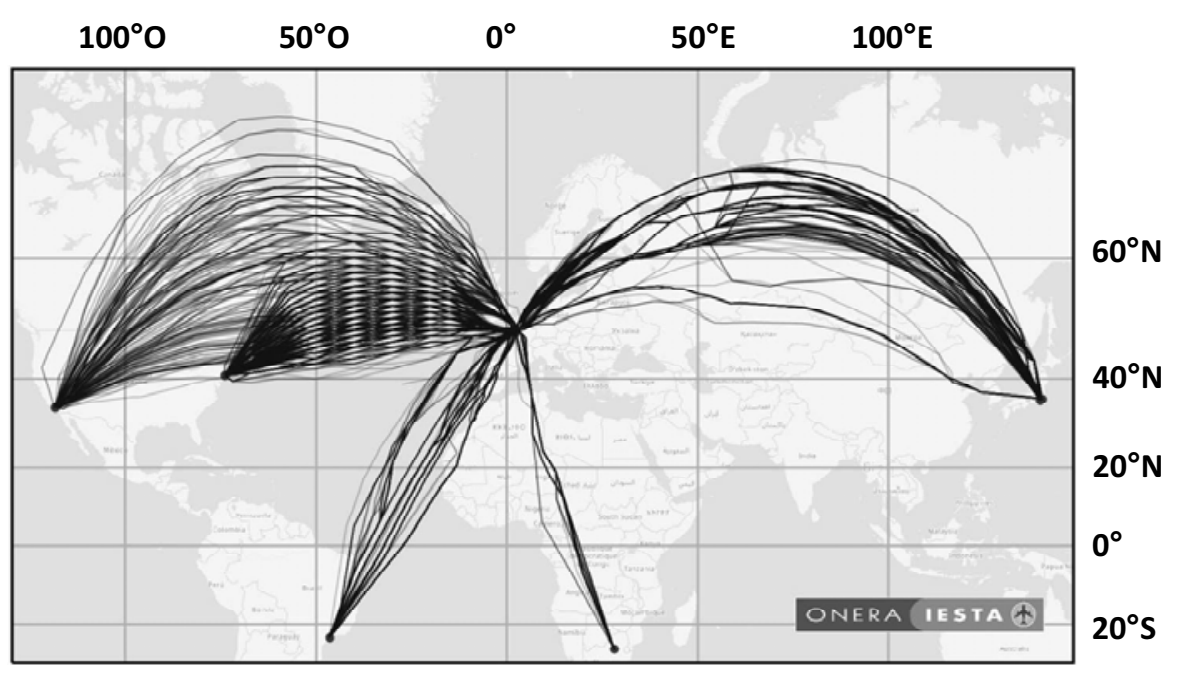

Fig. 7. World map of flight paths linking Paris to Los Angeles, New York, Tokyo, Johannesburg and Sao Paulo cities. 

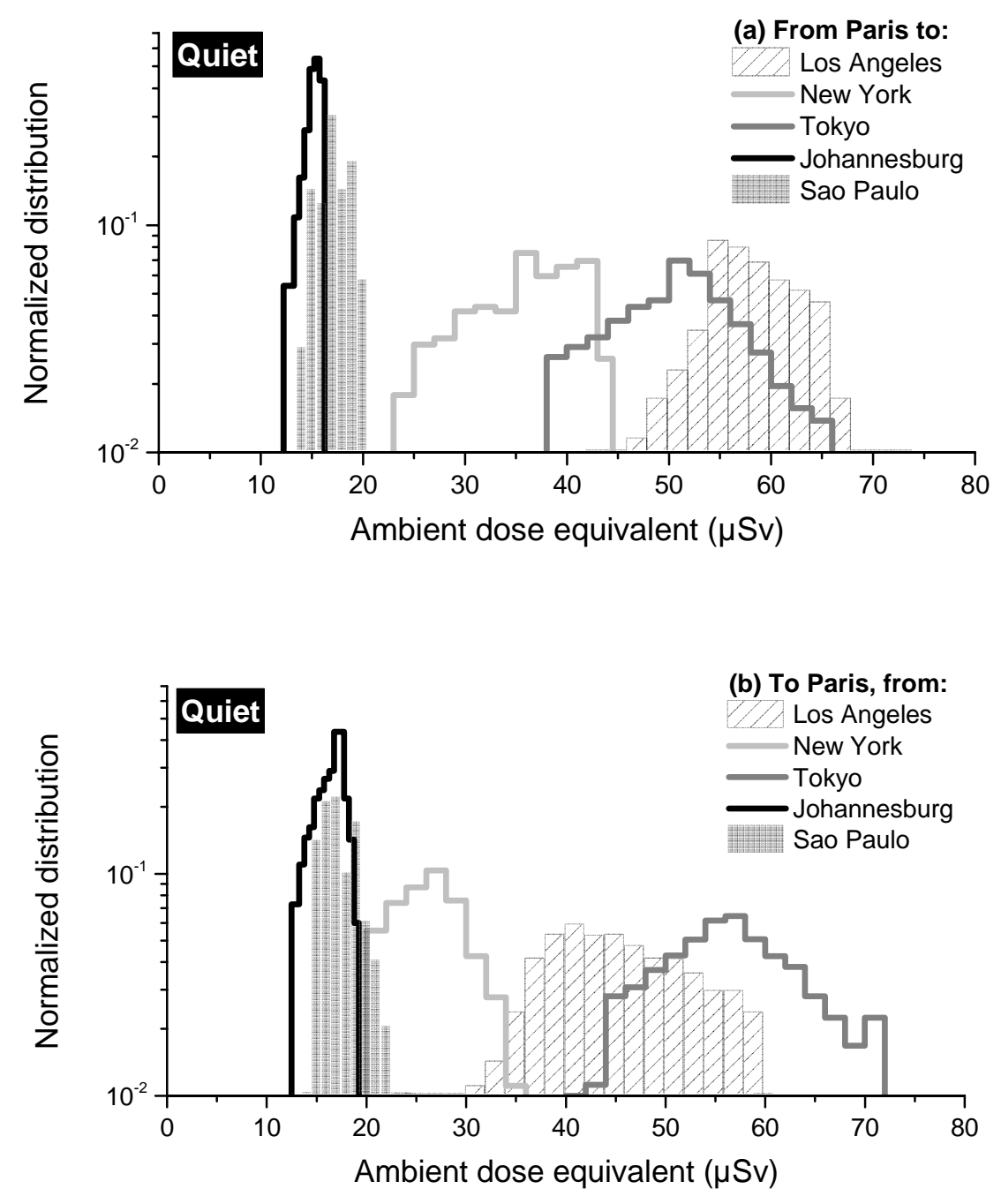

Fig. 8. Normalized distribution of the Ambient dose equivalent during quiet solar activity (solar modulation of $700 \mathrm{MV}$ ) and for five selected flight routes characterized by high number of paths (Paris to Los Angeles, New York, Tokyo, Johannesburg and Sao Paulo city). 

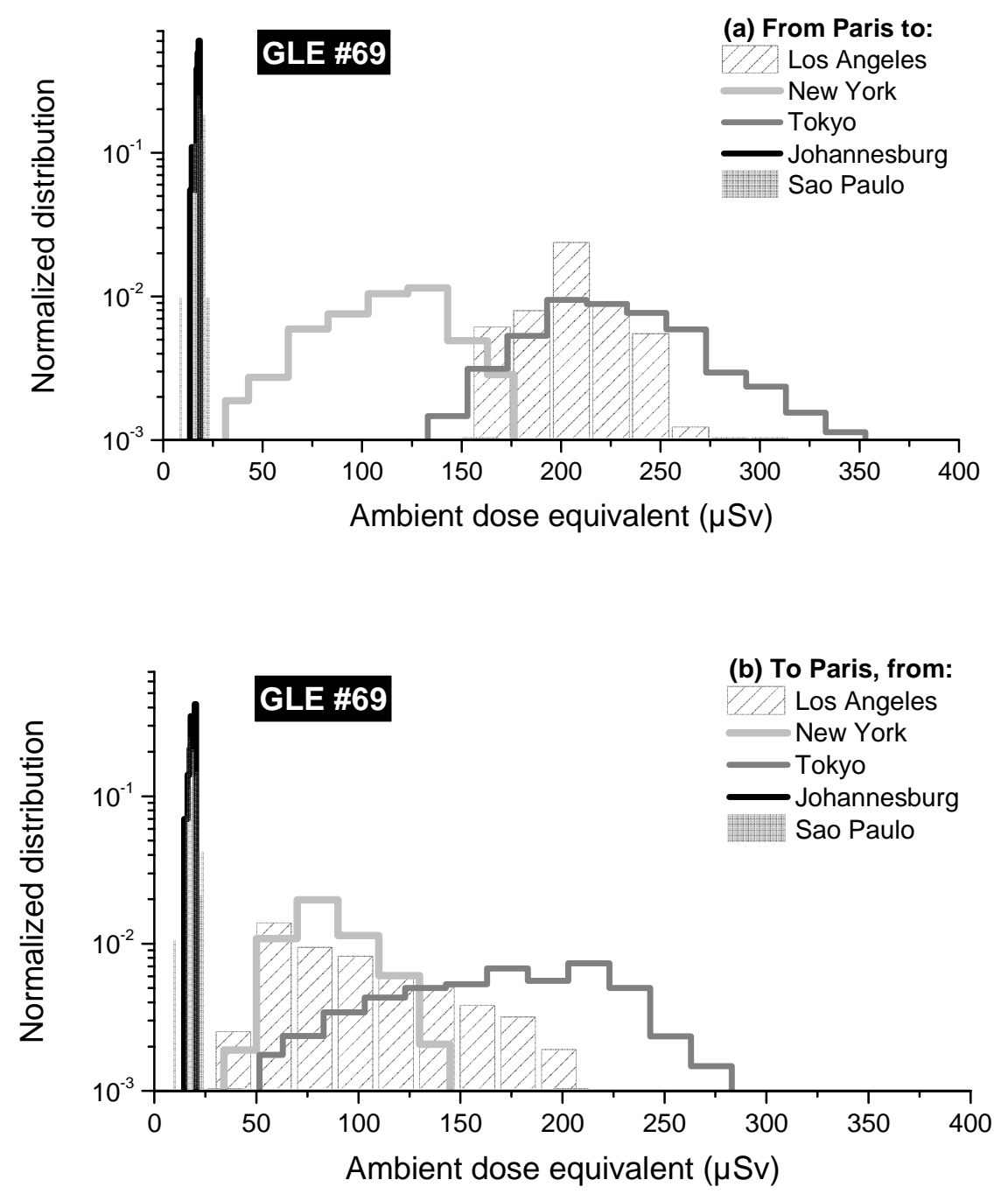

Fig. 9. Normalized distribution of the Ambient dose equivalent during the GLE \#69 event (delay of $4 \mathrm{~h}$ between the flight departure and the GLE occurrence) and for five selected flight routes characterized by high number of flights (Paris to Los Angeles, New York, Tokyo, Johannesburg and Sao Paulo city). 

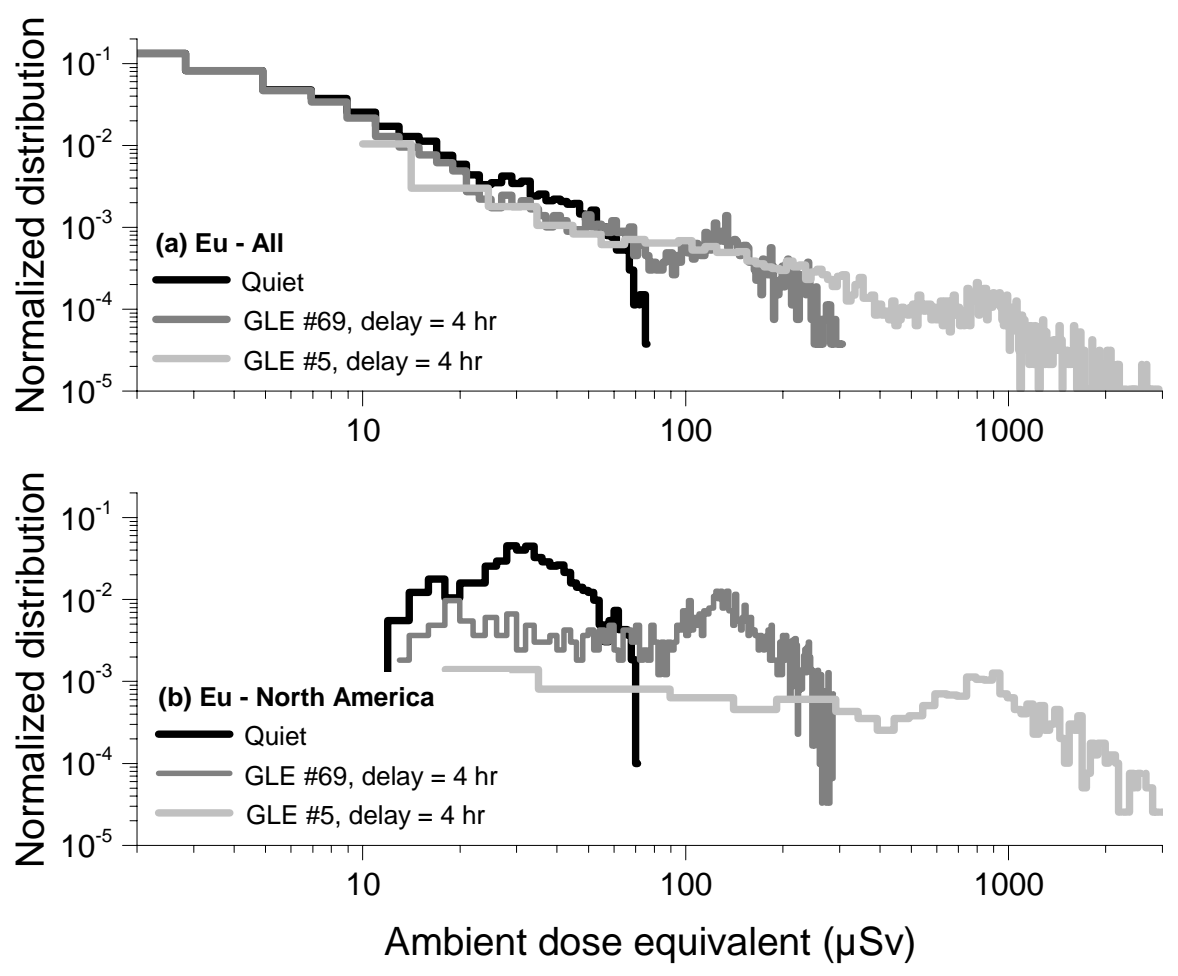

Fig. 10. Normalized ambient dose equivalent distribution considering the quiet solar period and the GLE \#69 with a delay of 4 hours. (a) all flights, and (b) Europe - North America flights. 

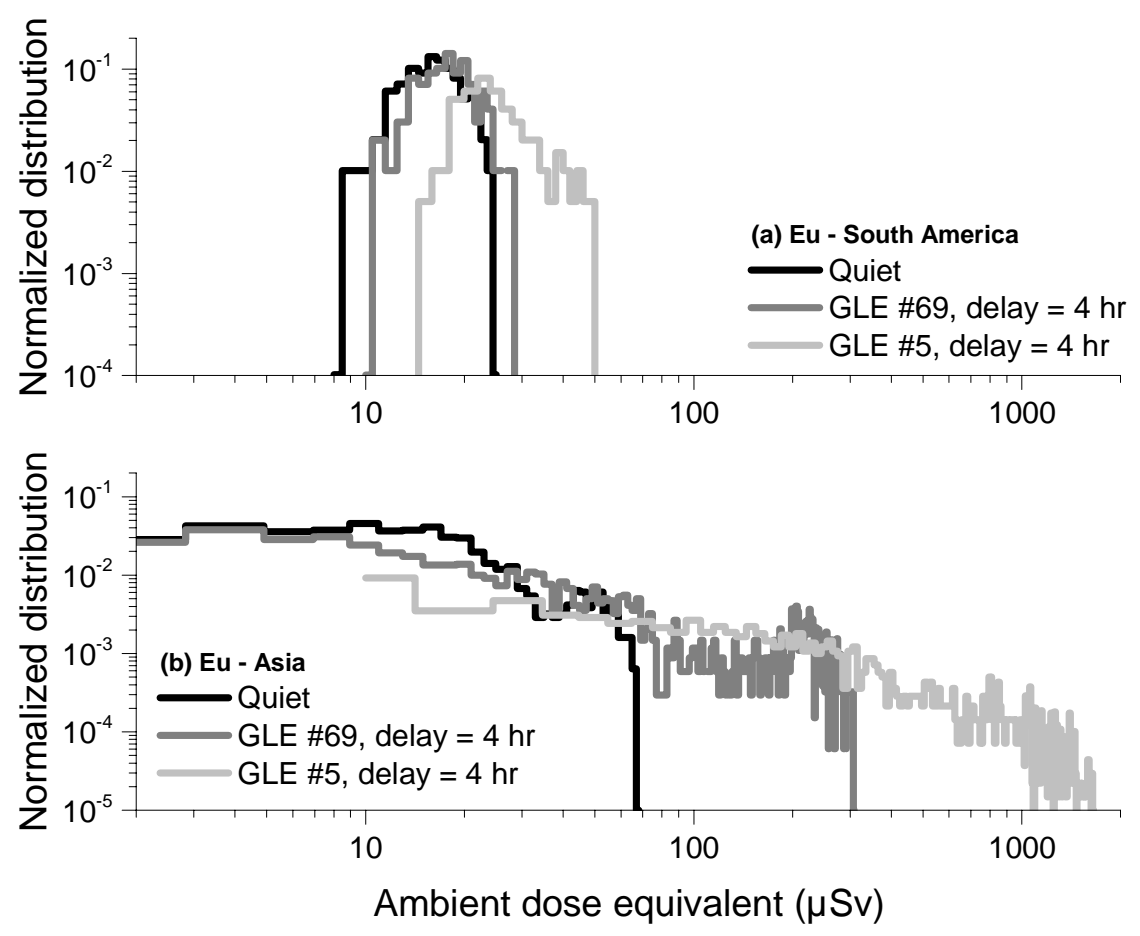

Fig. 11. Normalized ambient dose equivalent distribution considering the quiet solar period and the GLE \#69 with a delay of 4 hours. (a) Europe - South America, and (b) Europe - Asia flights. 

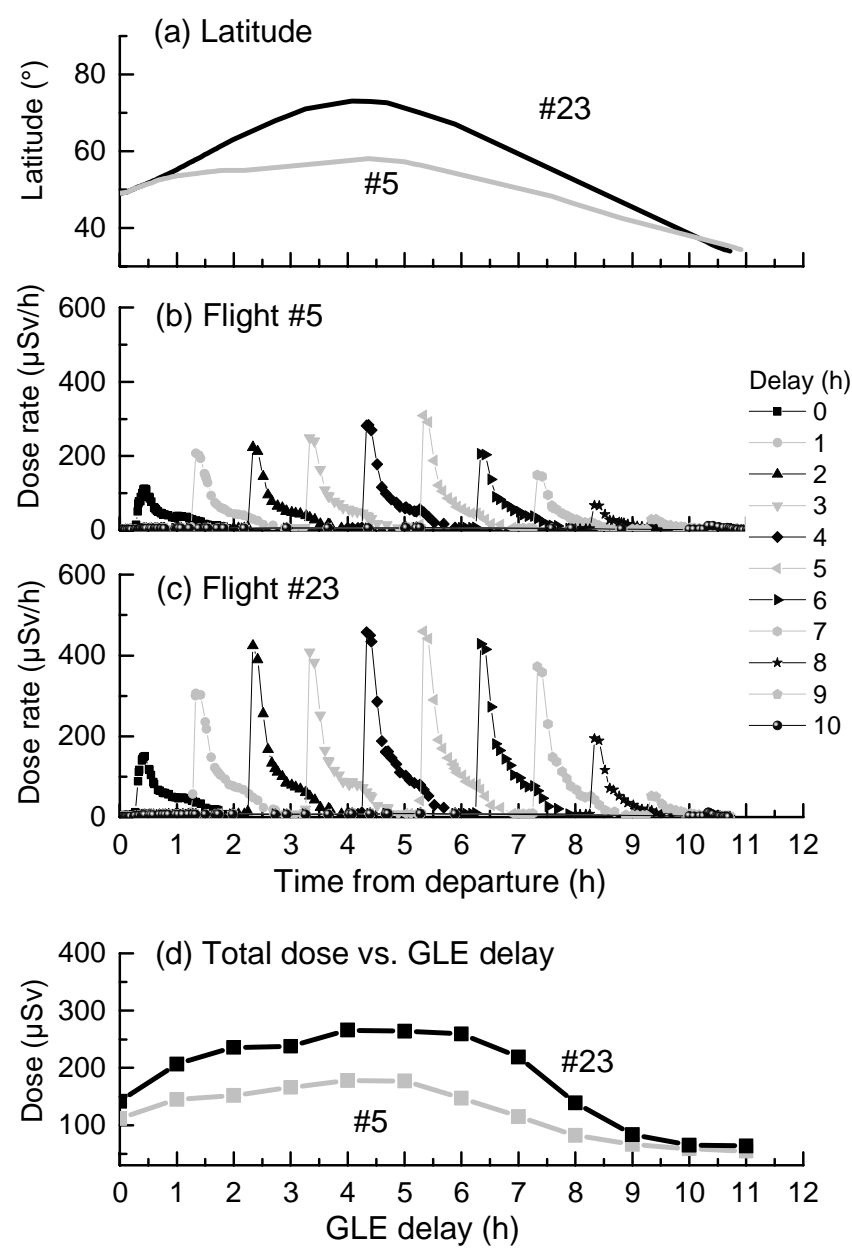

Fig. 12. (a) Paris-Los Angeles light route (\#5 and \#23), dynamics of the dose rate for flights \#5 (b) and \#23 (c) considering the GLE \#69 scenario for several occurrence delays (from 0 to $11 \mathrm{~h}$ ). Total ambient dose equivalents versus GLE delay (from 0 to $10 \mathrm{~h}$ ) are presented in $(\mathrm{d})$. 


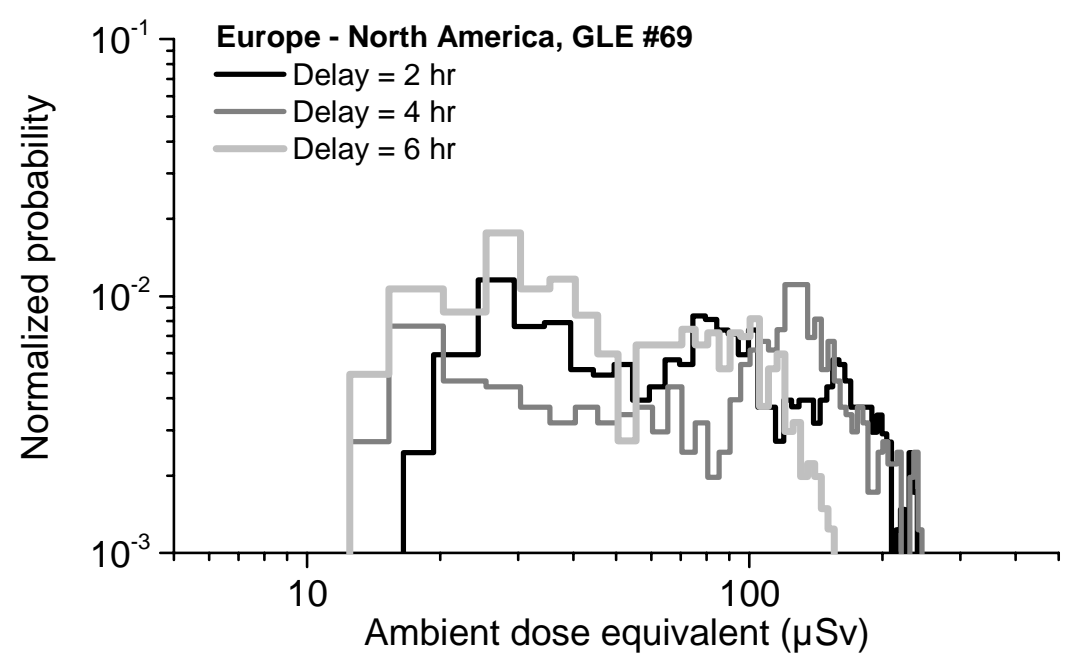

Fig. 13. Normalized distribution of the ambient dose equivalent considering several delays between the flight departure and GLE occurrence, 2, 4 and 6 hours respectively. Results concern the GLE \#69 and flights from or to North America.

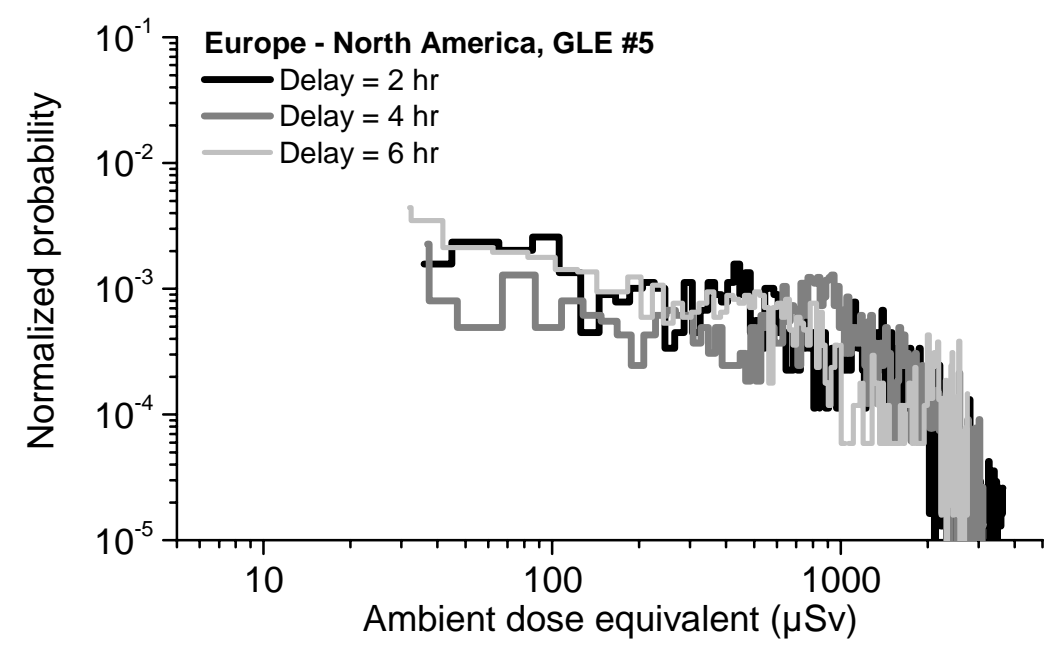

Fig. 14. Normalized distribution of the ambient dose equivalent considering several delays between the flight departure and GLE occurrence, 2, 4 and 6 hours respectively. Results concern the GLE \#5 (b) and flights from or to North America. 


\section{GCR and SCR model}

Extensive air shower simulations

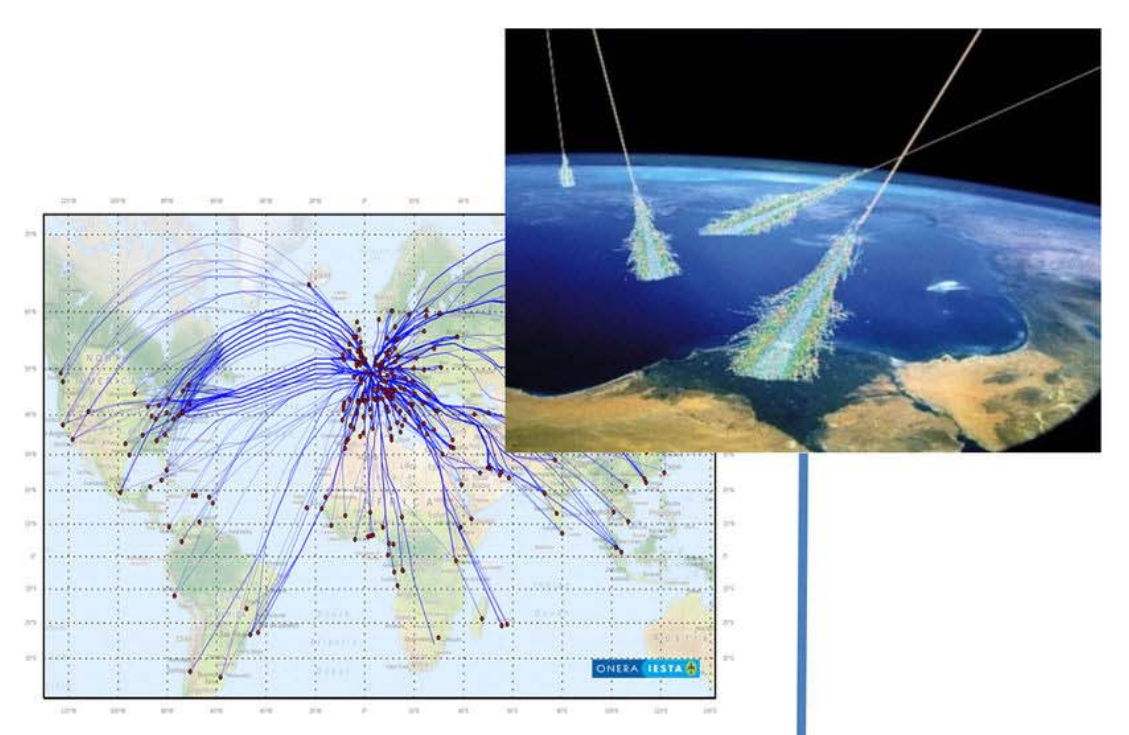

3. Fluence to ambient dose equivalent coefficients

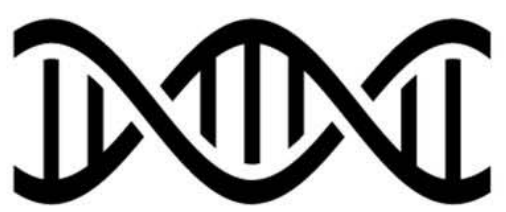

1. Flight path generator
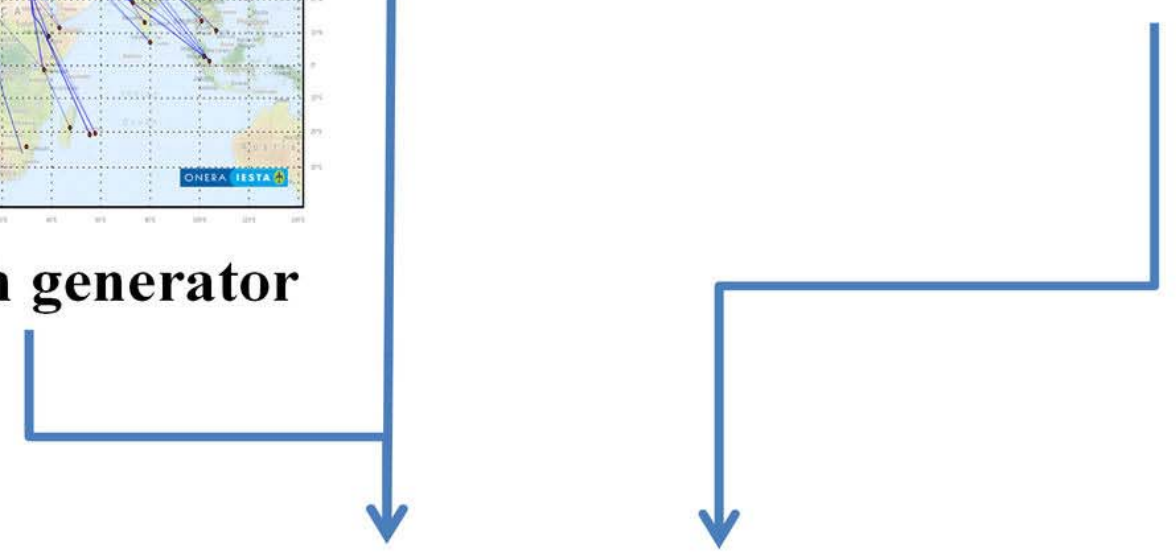

$$
H^{*}=\sum_{i=n, p, \mu, e} \int_{p a t h} \int_{E} \text { Spectrum }_{i} \times f_{i} \times \delta E \delta \text { path }
$$




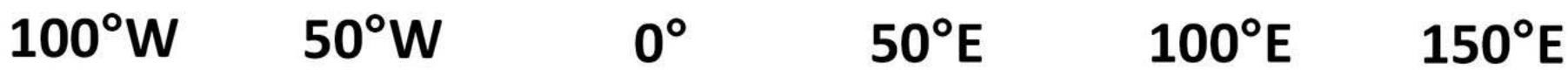

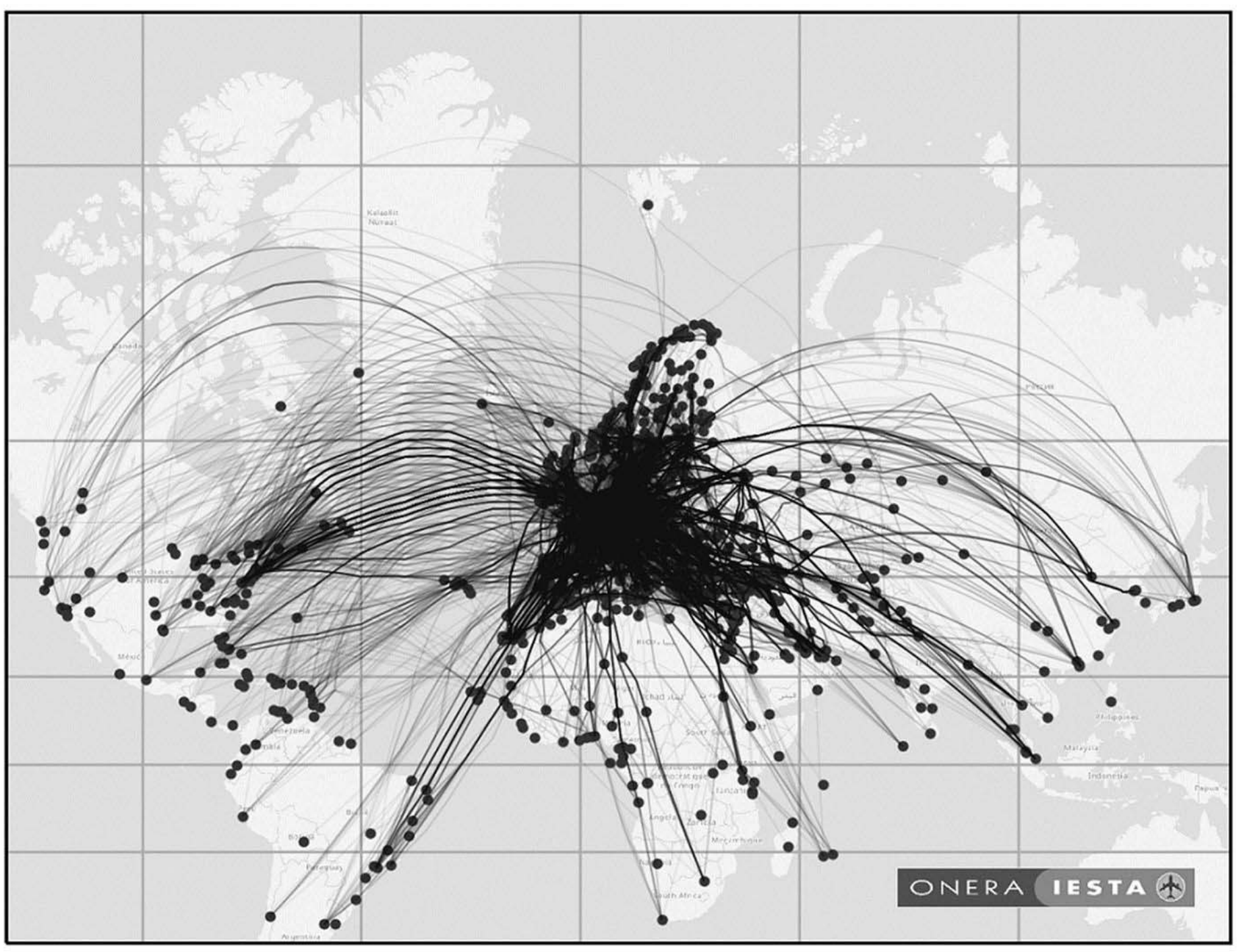

$80^{\circ} \mathrm{N}$

$60^{\circ} \mathrm{N}$

$40^{\circ} \mathrm{N}$

$20^{\circ} \mathrm{N}$

$0^{\circ}$

$20^{\circ} \mathrm{S}$

$40^{\circ} \mathrm{S}$ 


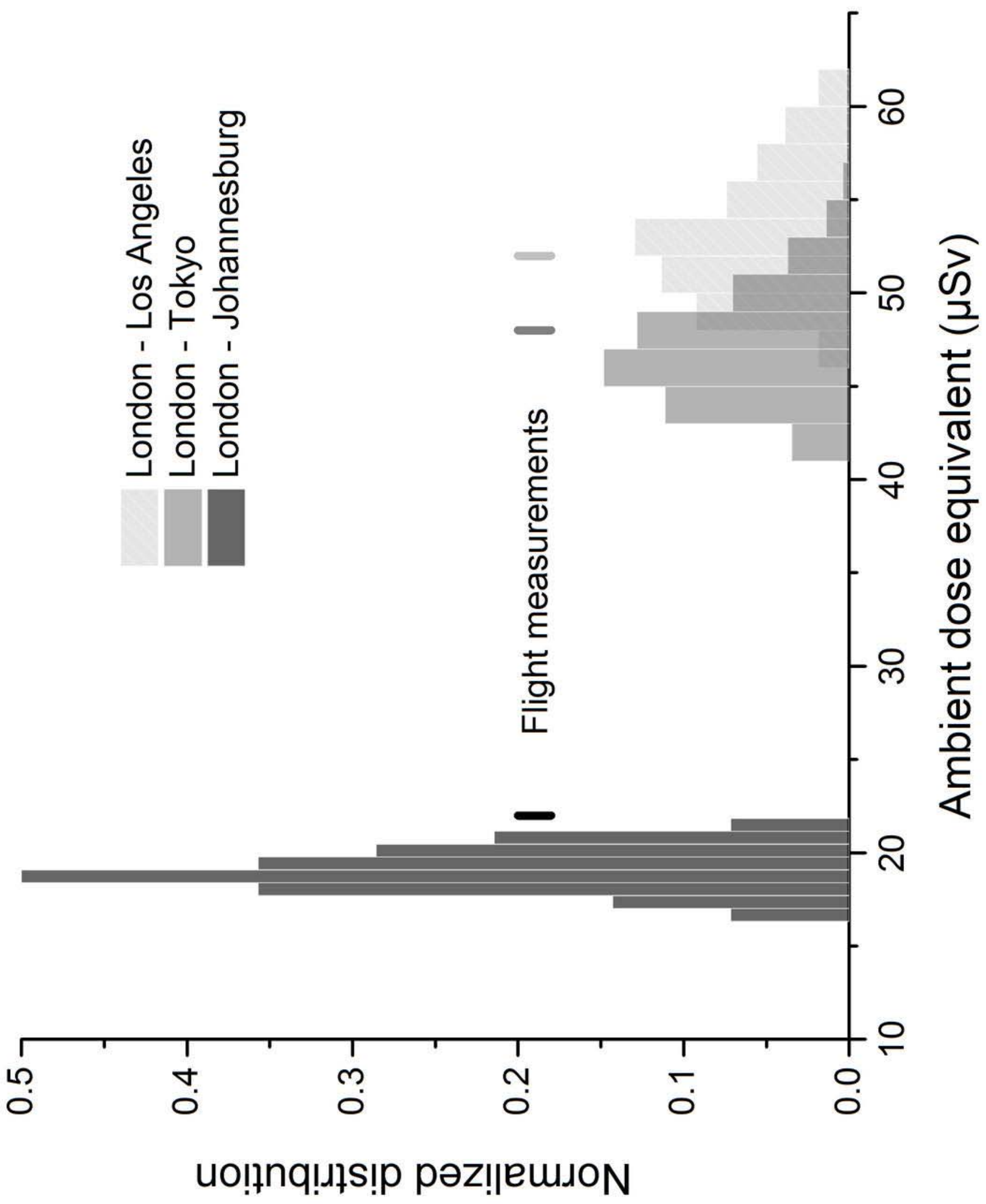




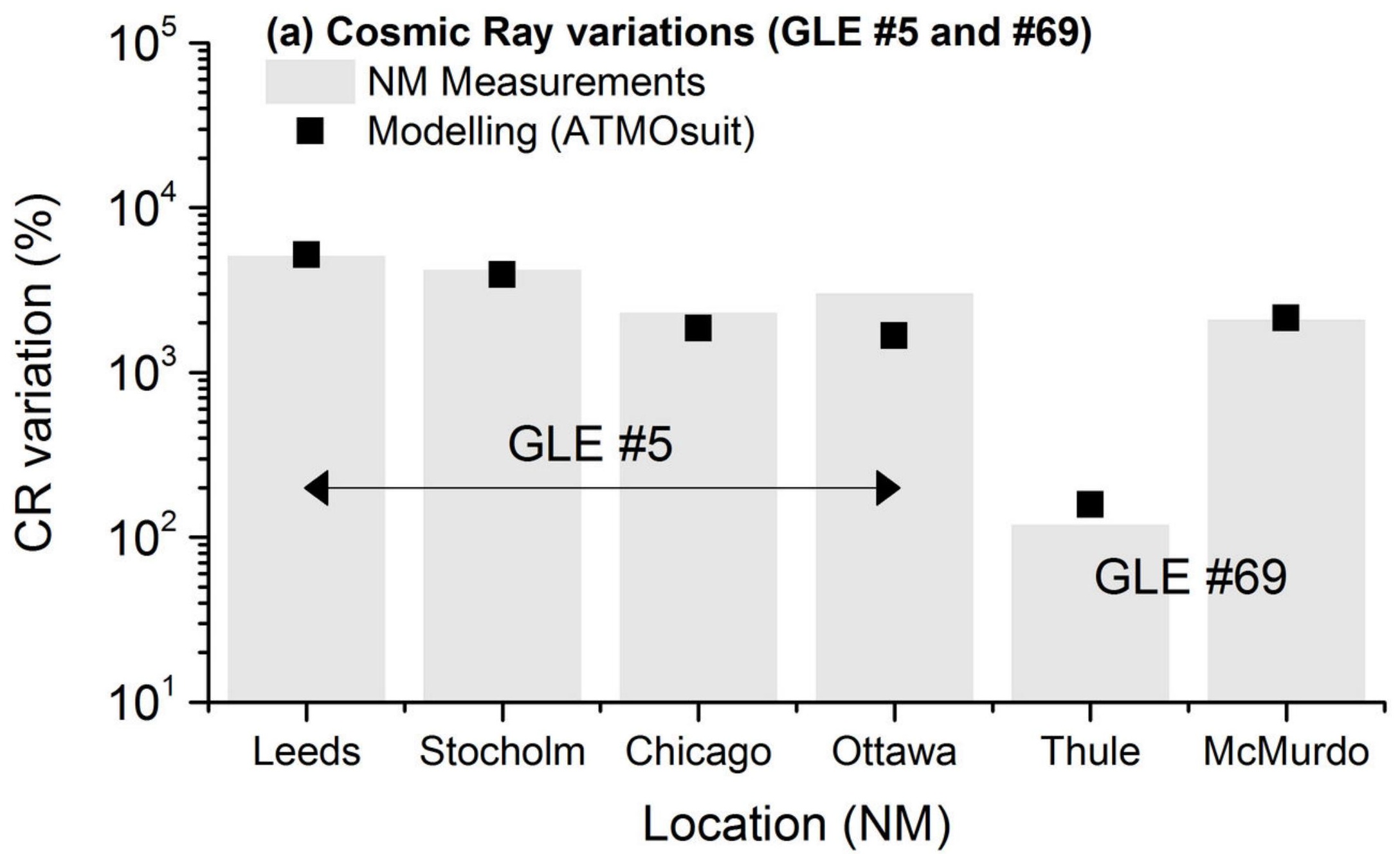




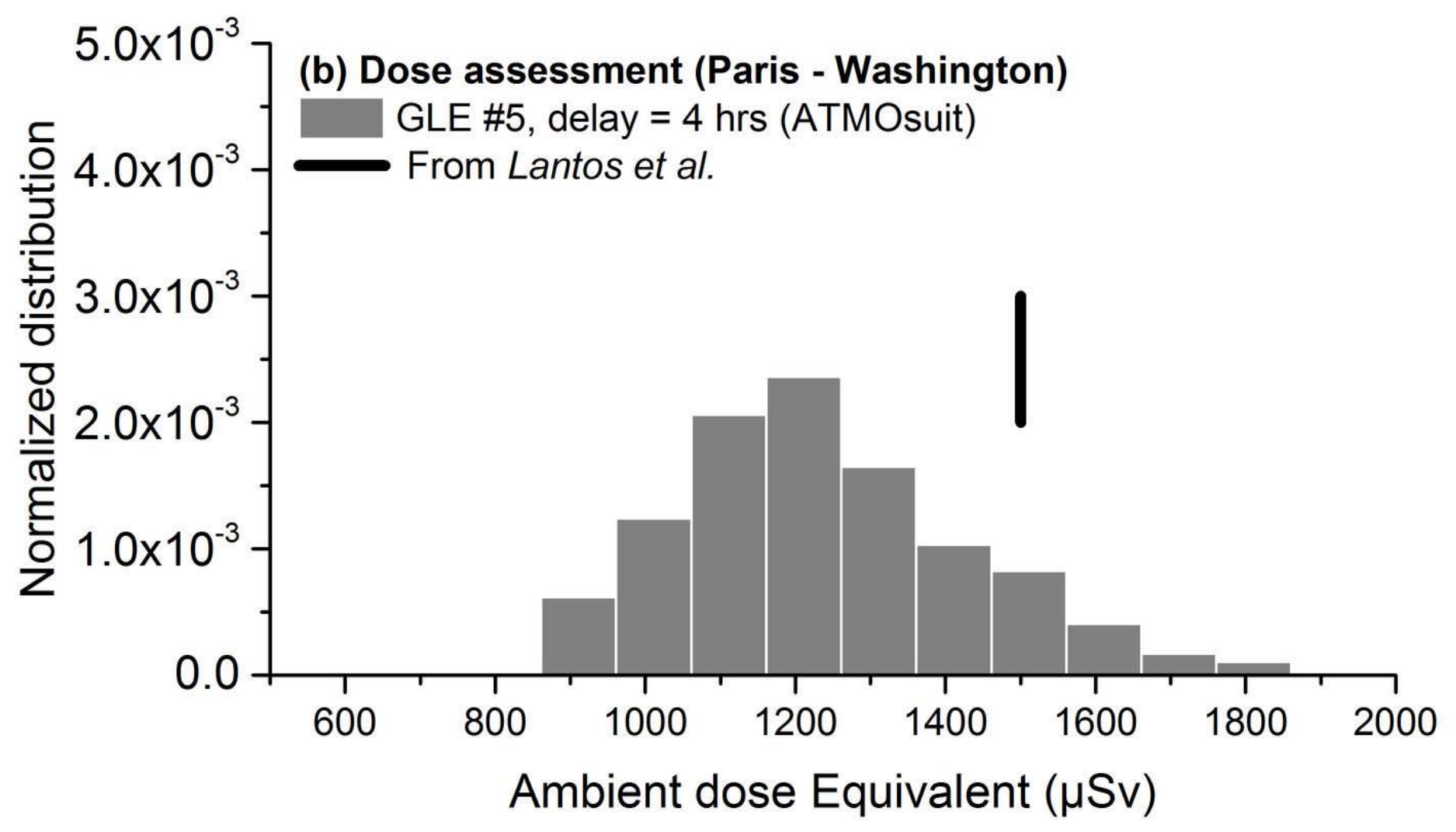




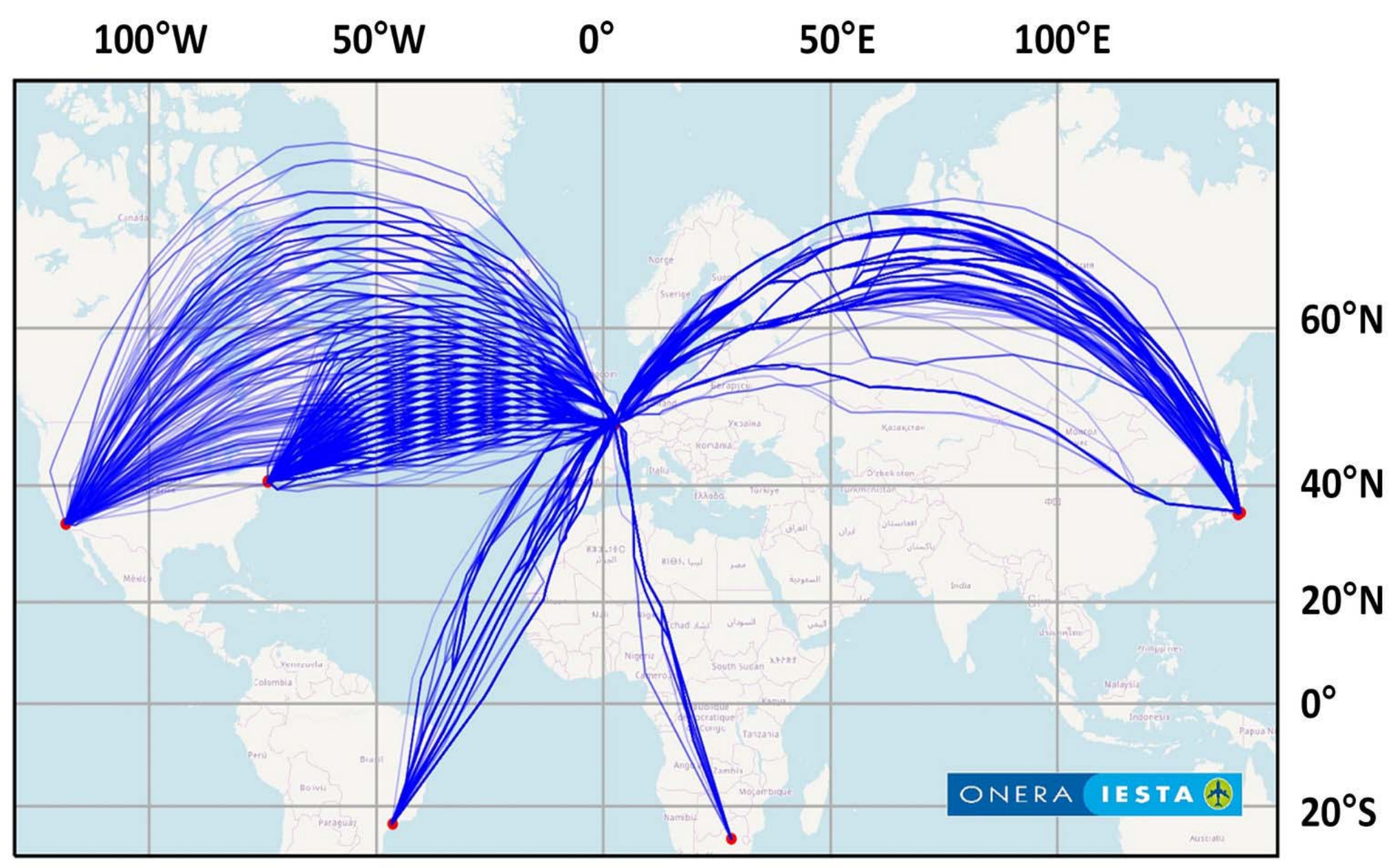


(a) Ambient dose equivalent ( $\mu \mathrm{Sv}$ )

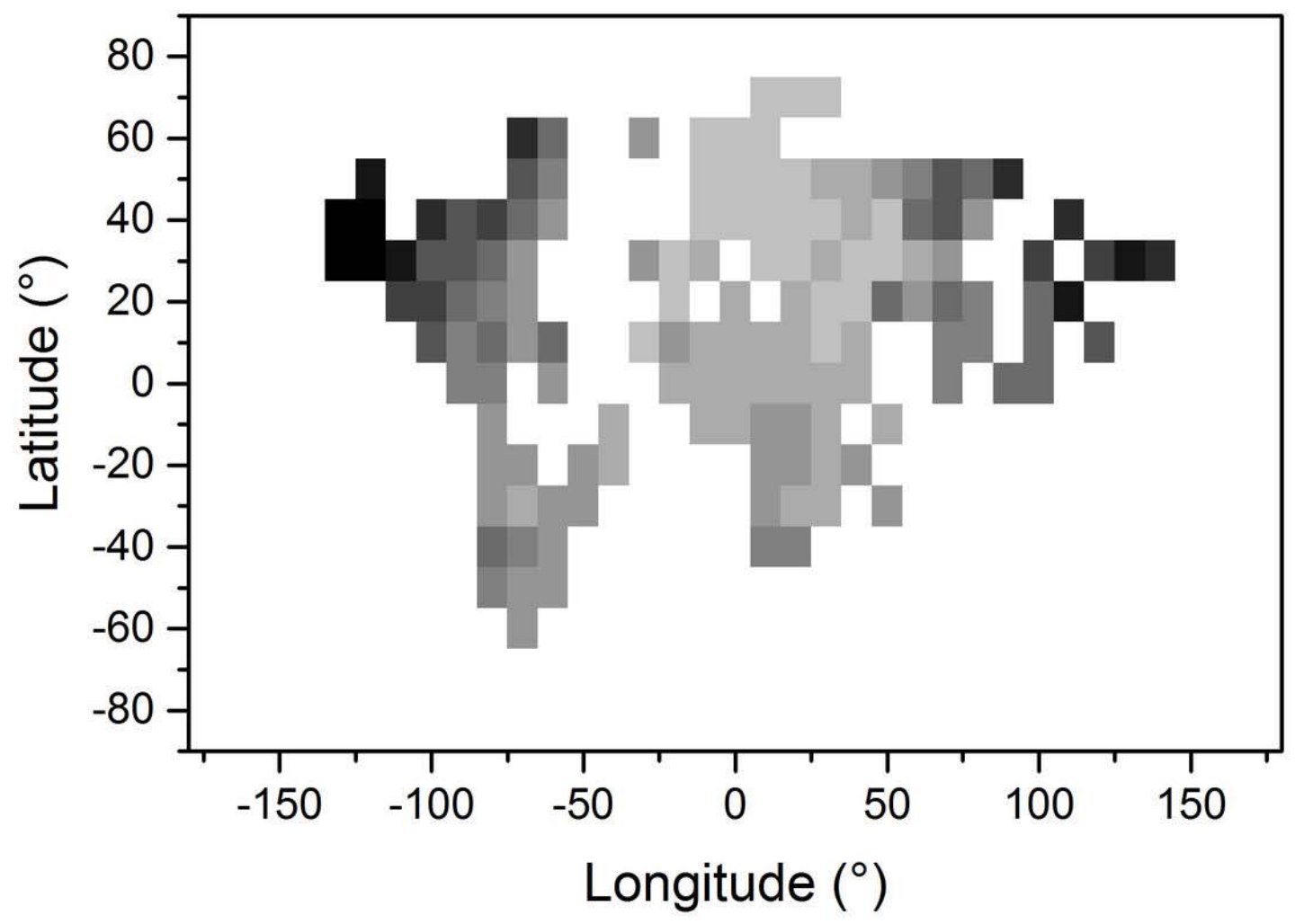




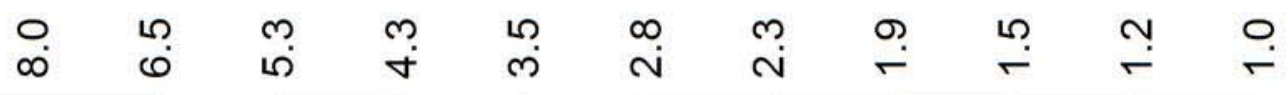

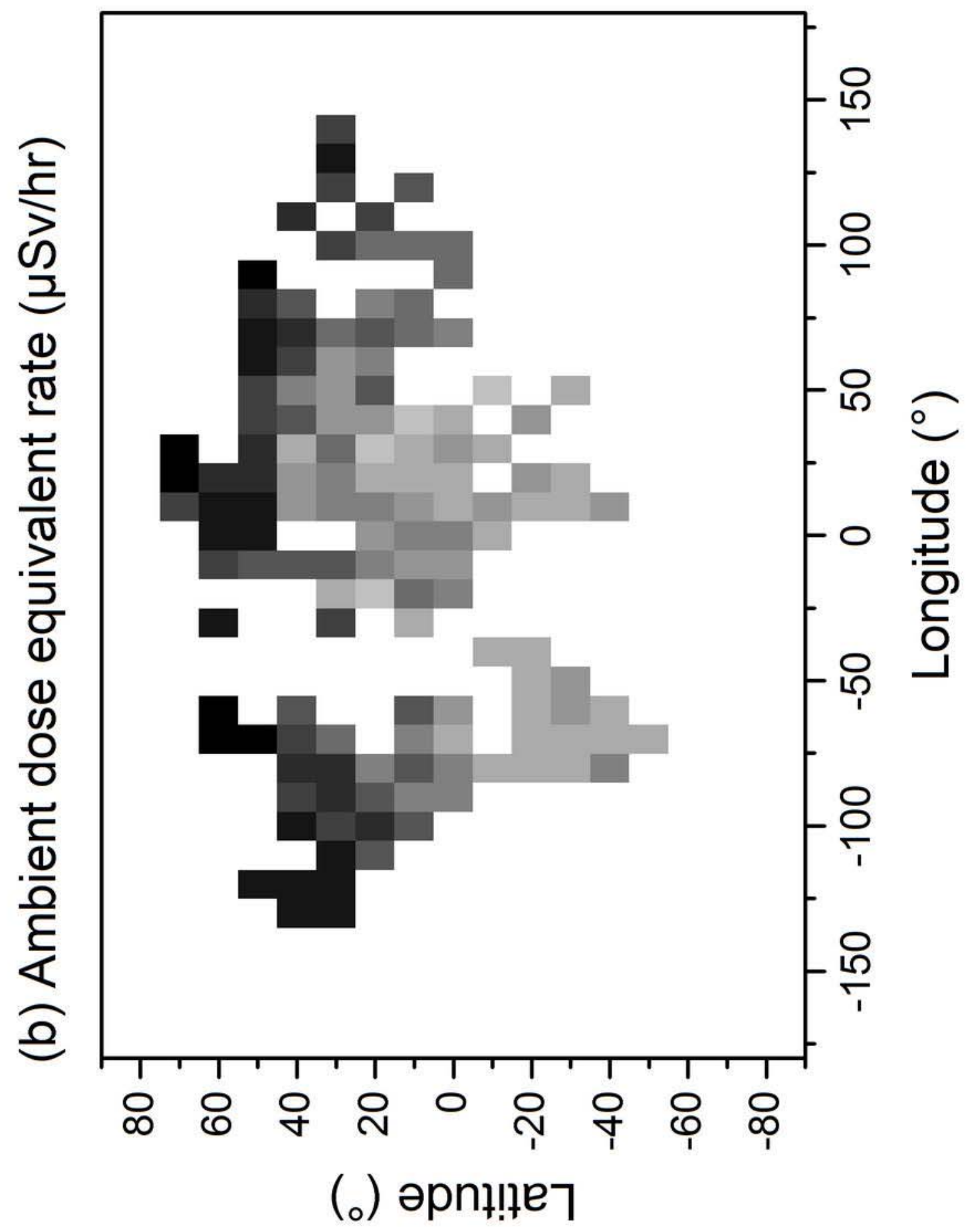



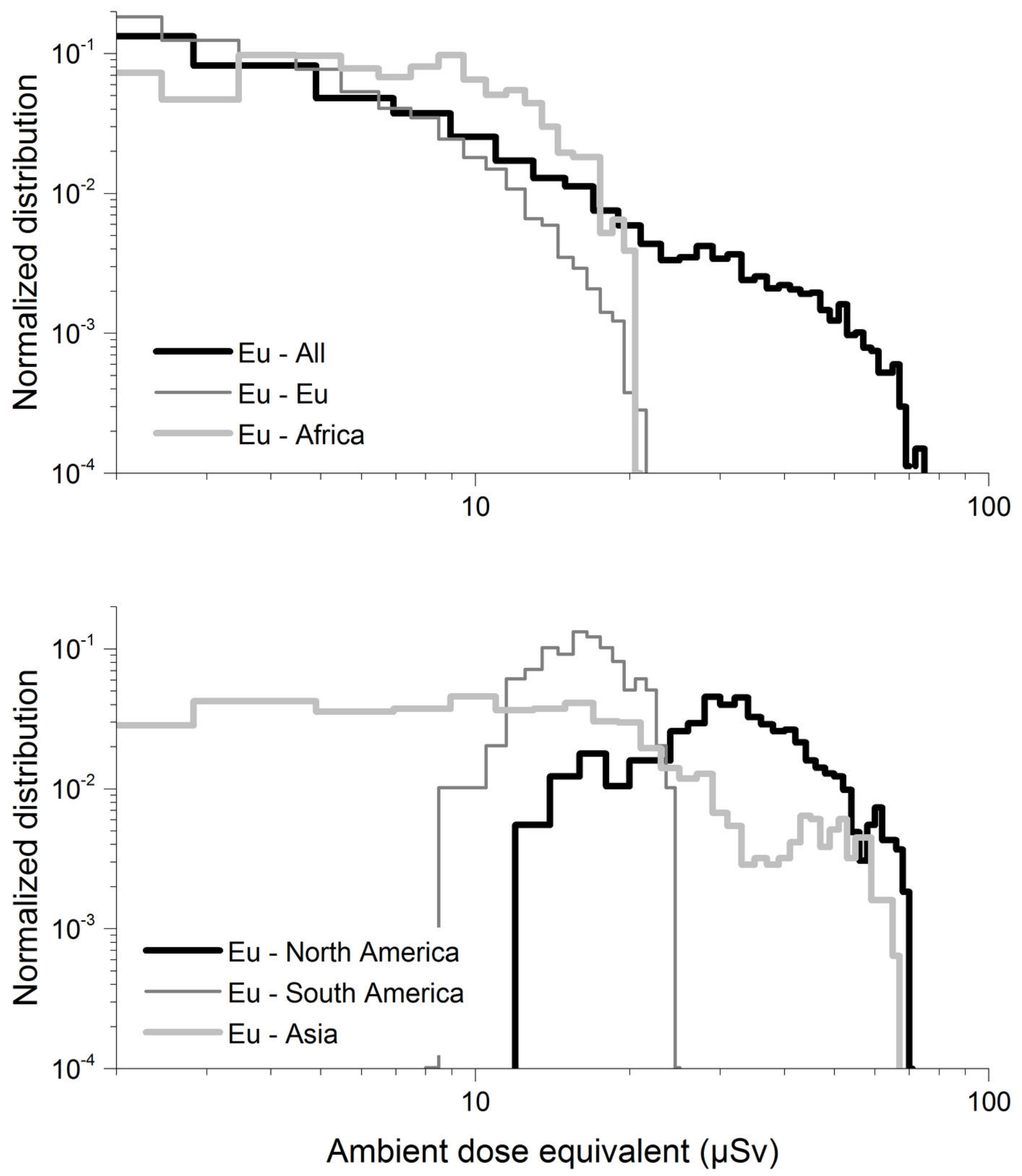


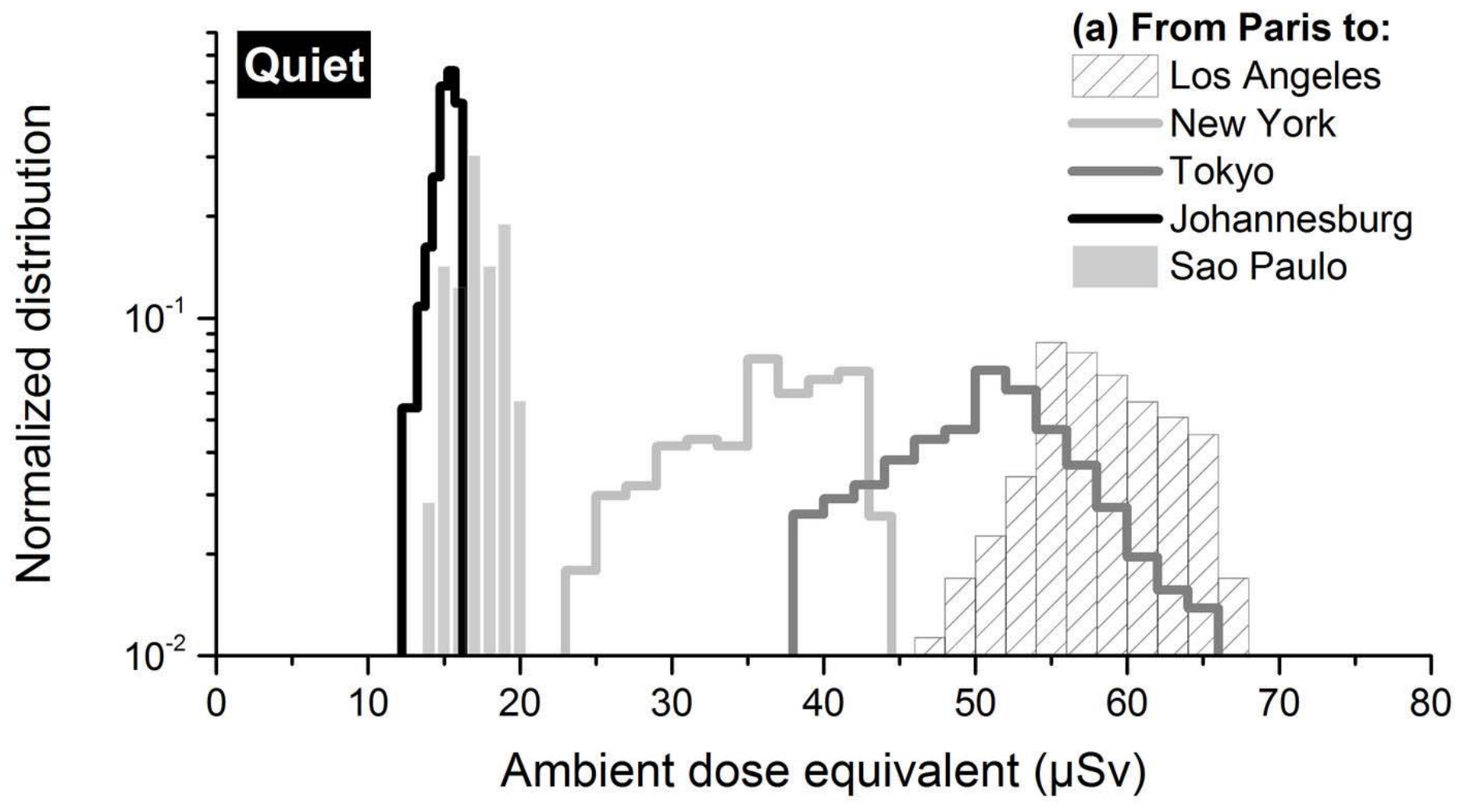




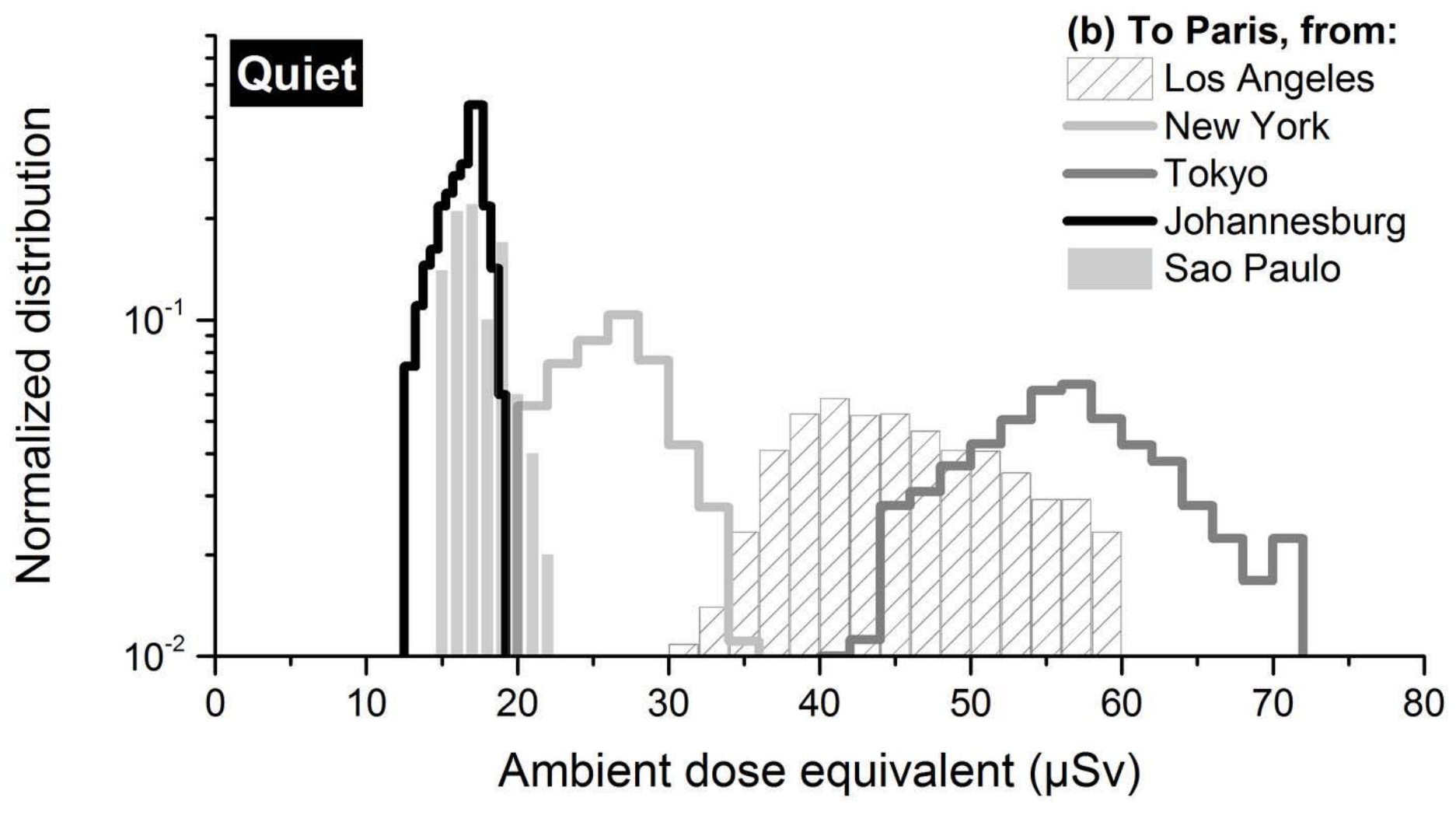



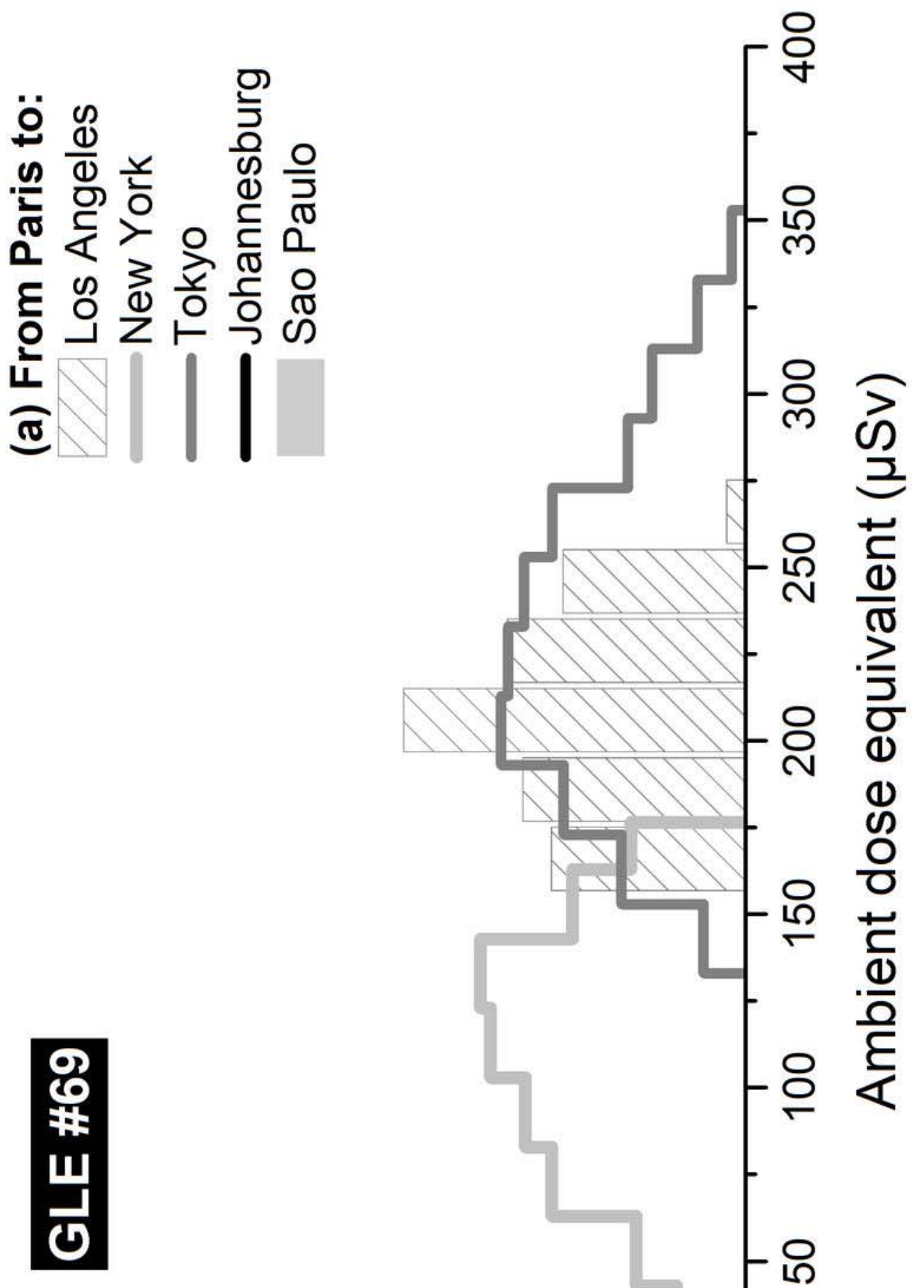

uo!̣nq!ııs!p pəz!|euıoN 


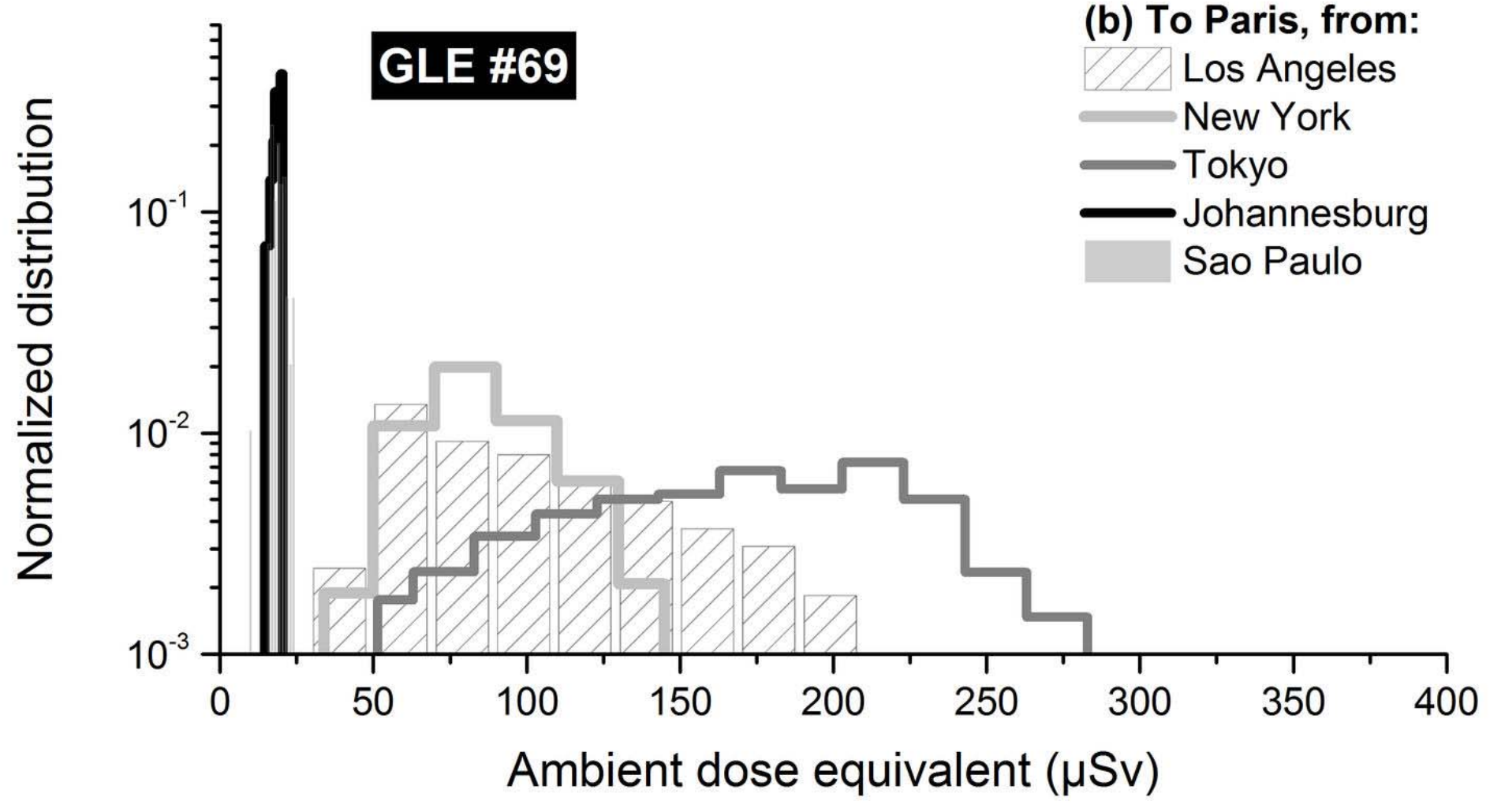



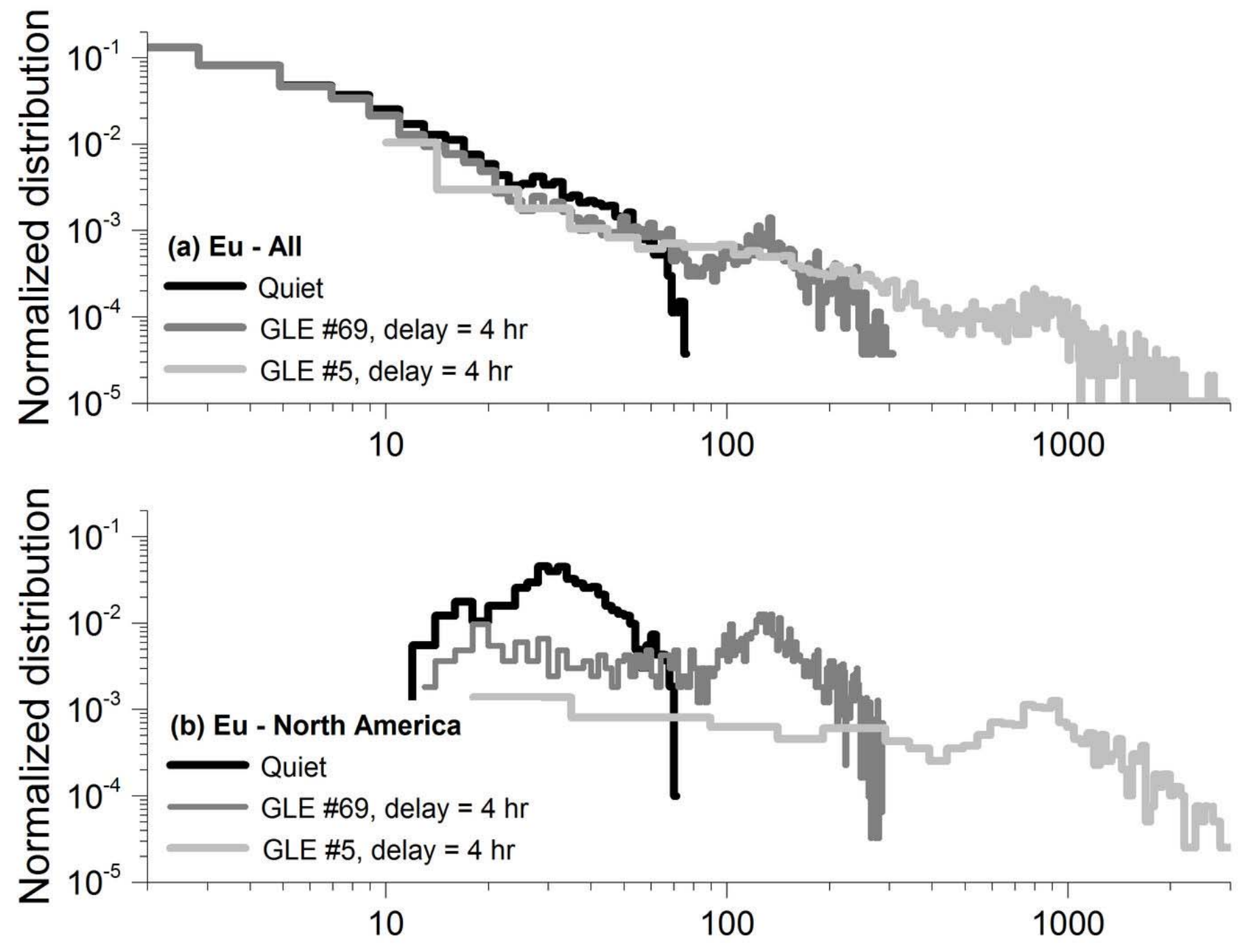

Ambient dose equivalent ( $\mu \mathrm{Sv}$ ) 


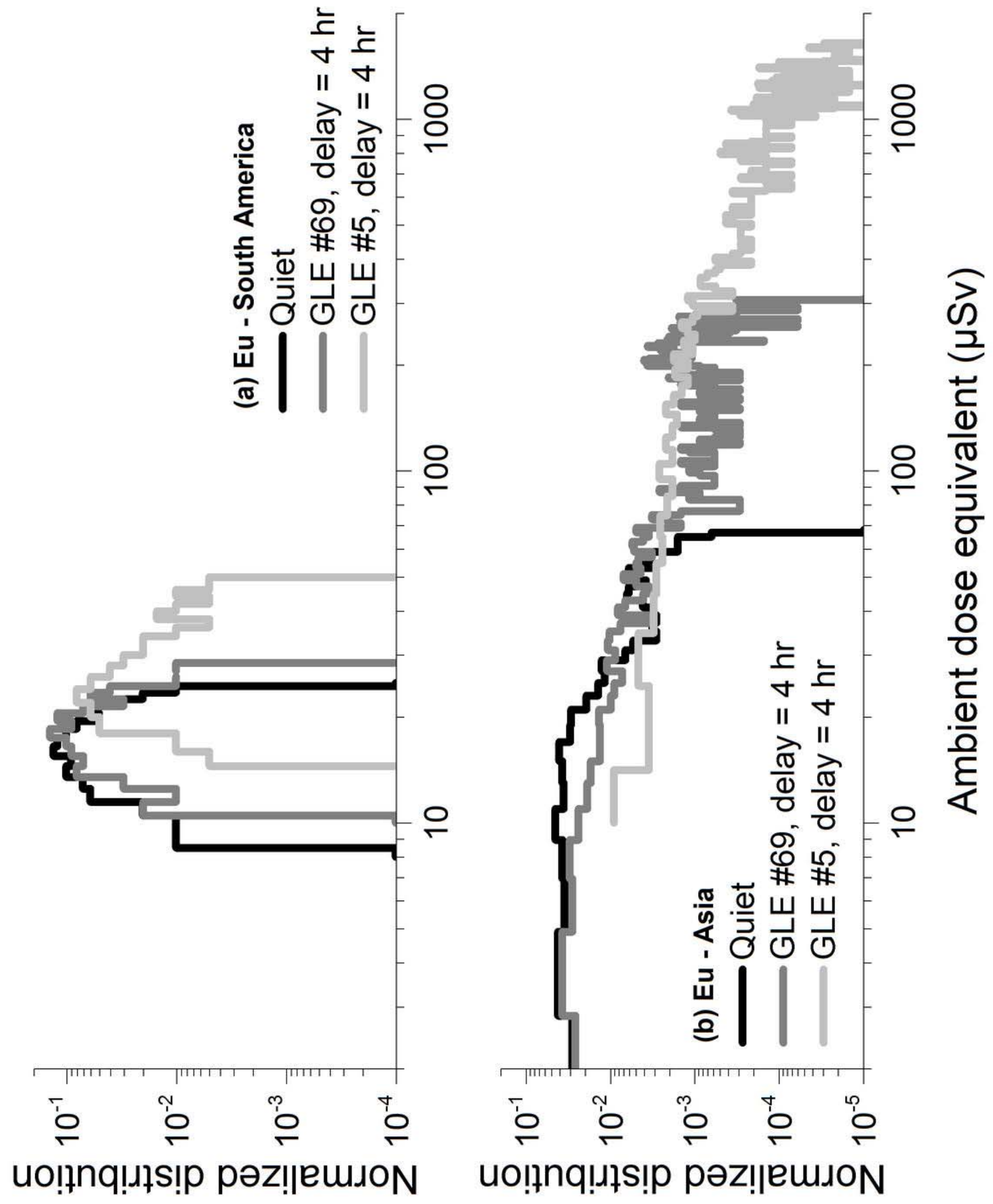




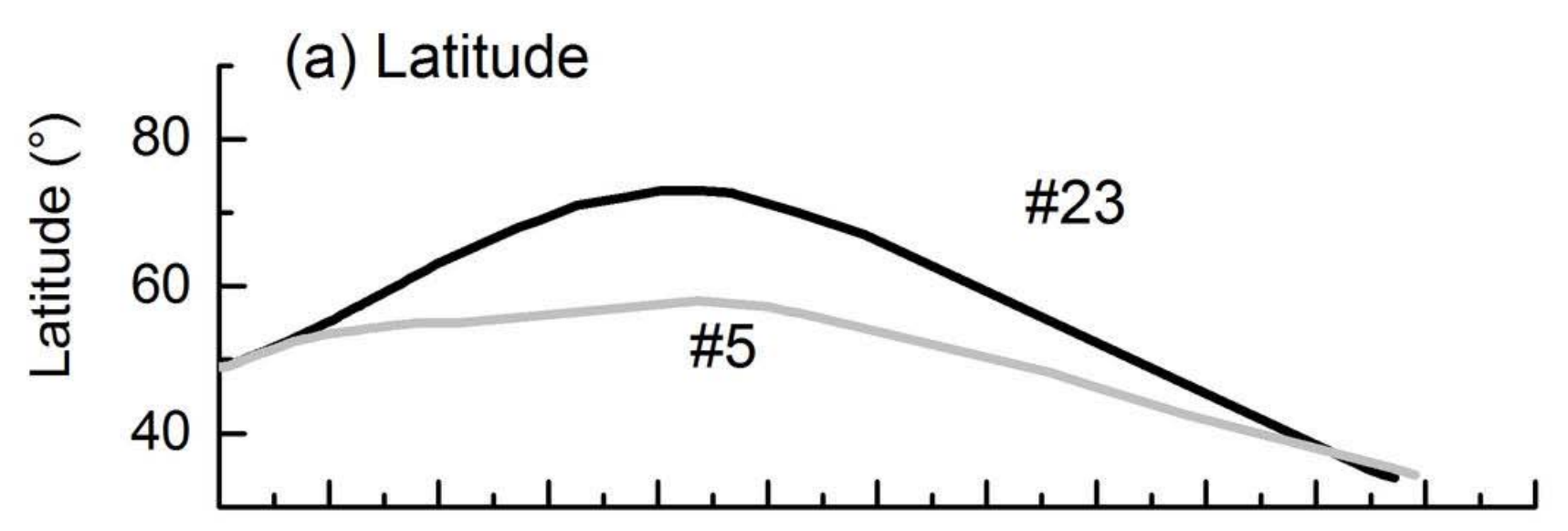

c) 600 [ (b) Flight \#5
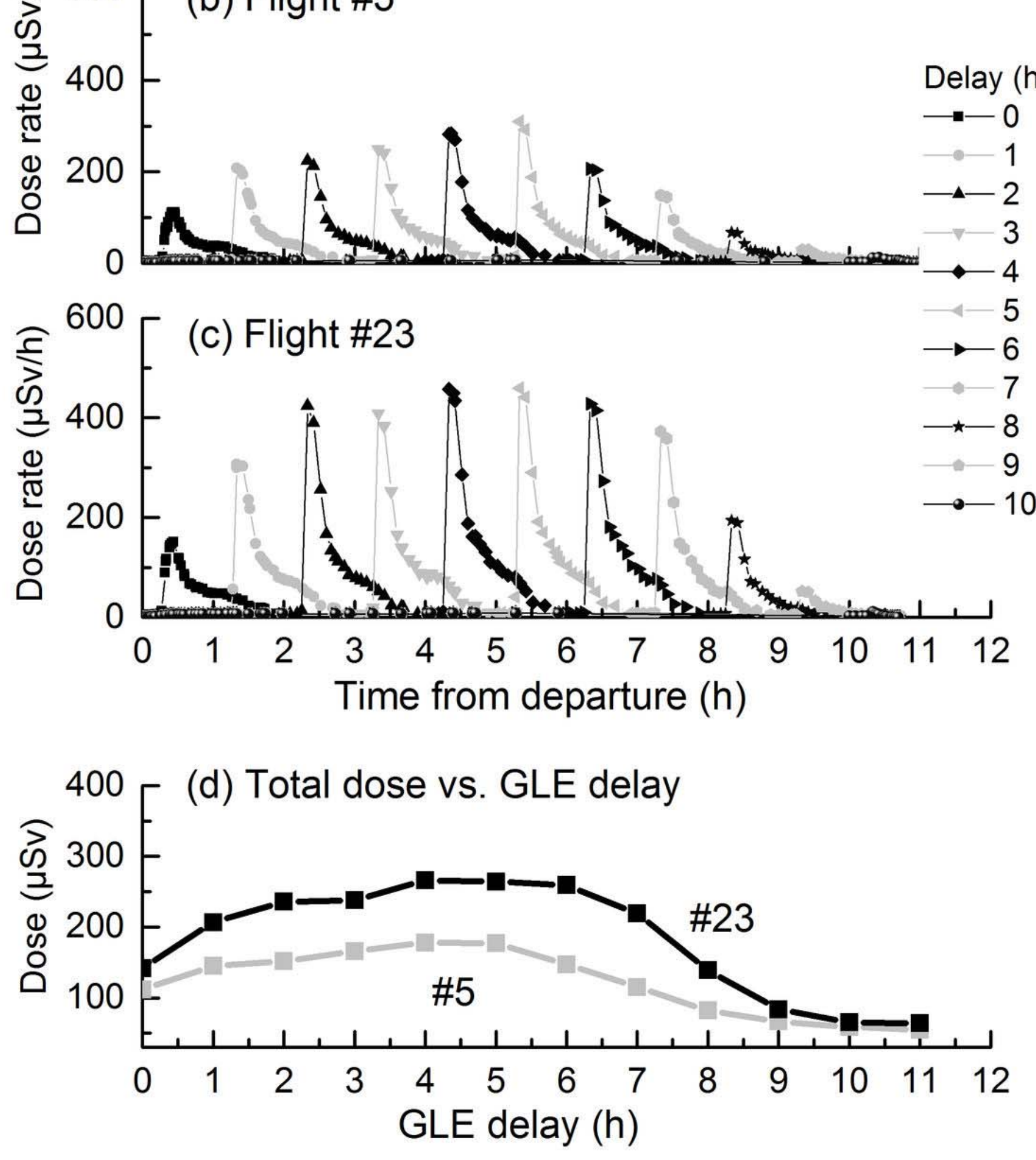


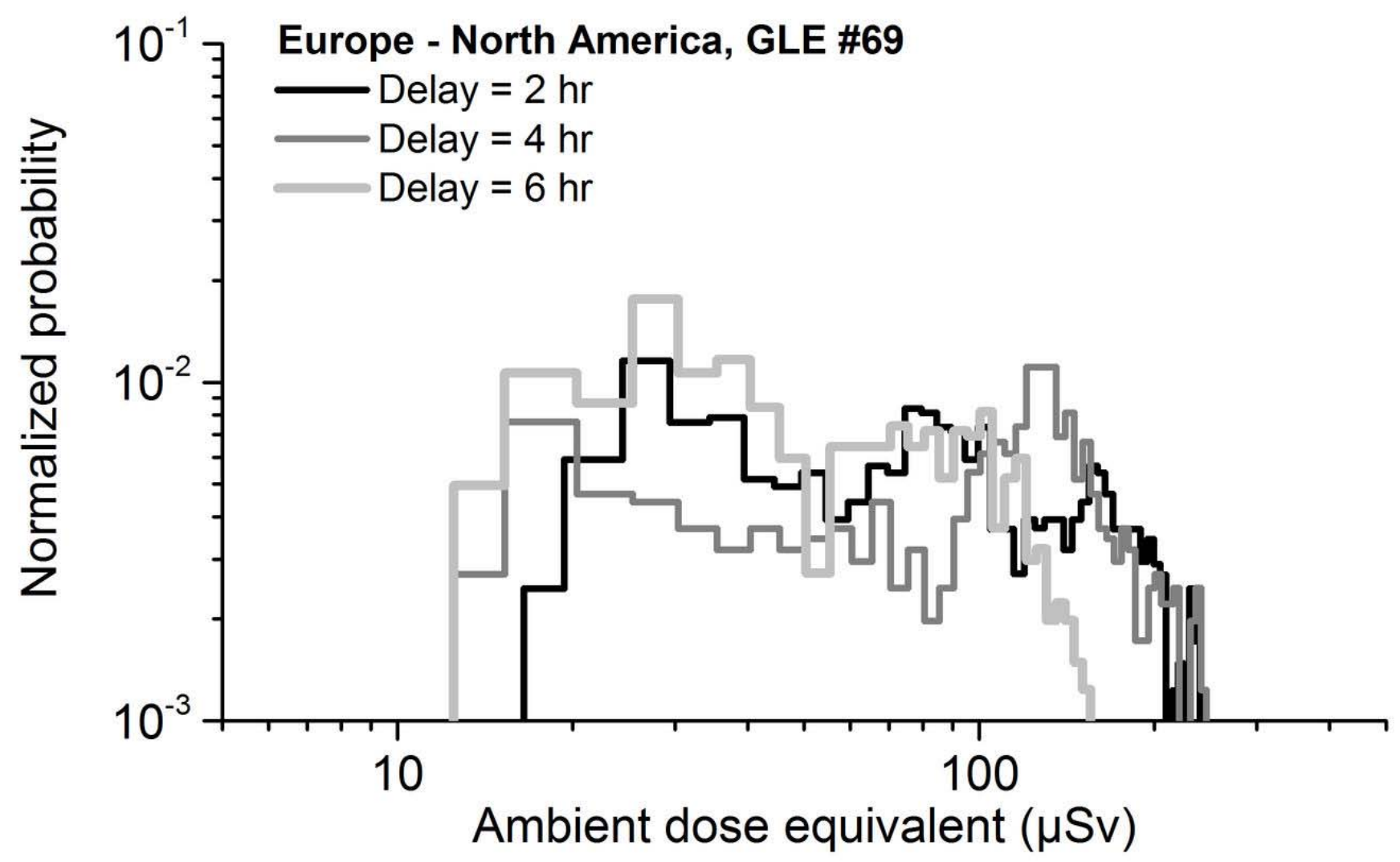




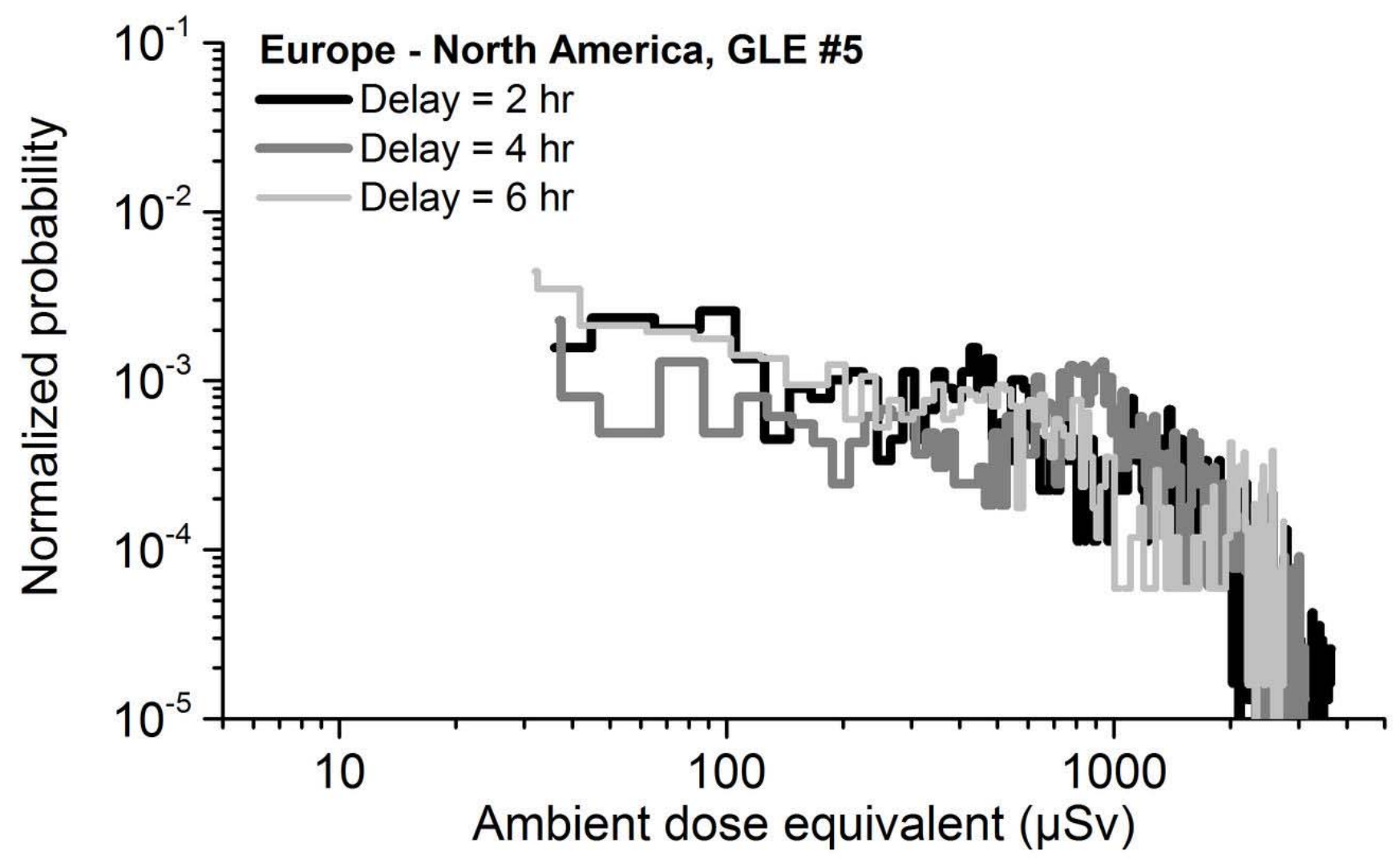

